\section{Revista de CIENCIAS AMBIENTALES Tropical Journal of Environmental Sciences}

Revista de Ciencias Ambientales (Trop J Environ Sci) e-ISSN: 2215-3896

(Enero-Junio, 2022) . Vol 56(1): 178-208

DOI: https://doi.org/10.15359/rca.56-1.9

Open Access: www.revistas.una.ac.cr/ambientales e-mail: revista.ambientales@una.ac.cr

Rodríguez-Gonzales A., Zárate-Villarroel S., Bastida-Codina A.

\title{
Biodiversidad bacteriana presente en suelos contaminados con hidrocarburos para realizar biorremediación
}

\author{
Bacterial biodiversity present in soils contaminated with hydrocarbons to carry out \\ bioremediation
}

\author{
Apolonia Rodríguez-Gonzales ${ }^{1}$, Sandra Giovana Zárate-Villarroel ${ }^{2}$, \\ Agatha Bastida-Codina ${ }^{3}$
}

[Recibido: 26 de septiembre 2021, Aceptado: 25 de octubre 2021, Corregido: 8 de noviembre 2021, Publicado: 1 de enero 2022]

\section{Resumen}

[Introducción]: La biorremediación es una tecnología que utiliza microorganismos (bacterias, hongos, algas) o enzimas, para biodegradar contaminantes del petróleo y derivados y como otros contaminantes que están presentes en suelo, aire o agua. En América Latina, existe un alto grado de contaminación de sus ecosistemas; por tanto, esta tecnología es viable económica y ambientalmente para degradar contaminantes. Los hidrocarburos aromáticos policíclicos como asfaltenos y resinas son difíciles de degradar, así como los alifáticos y bifenilos policlorados. [Objetivo]: Se busca dar una visión general de las publicaciones recientes sobre investigaciones científicas realizadas y metodologías de biorremediación de suelos contaminados por petróleo y sus derivados. [Metodología]: Se realizó una búsqueda exhaustiva de la literatura científica de los últimos años, relacionada con el tema propuesto en bases de datos bibliográficas: Medline, Current Contents, PubMed, Google scholar, SciFinder, Scopus y en revistas especializadas: Chemosphere, Microbiología Aplicada, Biodegradation \& Biodeterior, Sociedad Americana de Microbiología, Microbiología Frontal, Sci Total Environ. Las palabras clave utilizadas fueron en español o inglés. [Resultados]: Los hidrocarburos poliaromáticos pueden ser biodegradados por diferentes bacterias que biodegradan solas o en consorcio, como el fenantreno (compuesto aromático) que fue biodegradado por 11 cepas bacterianas diferentes (Sphingobium, Sphingomonas, Acidovorax, Alkaligenes, Actinobacteria, Burkholderia sp., Rhizobium sp., Pseudomonas sp., Stenotrophomonas y Sinorhizobium). En biorremediación, se considera importante las variables fisicoquímicas, como el $\mathrm{pH}$, temperatura, oxígeno y la humedad, al ser factores que influyen en el éxito del tratamiento. [Conclusiones]: Se buscó aportar con esta revisión, soluciones viables a variados problemas de contaminación por hidrocarburos de los ecosistemas latinoamericanos.

Palabras clave: Contaminantes; ecosistemas; metabolismo; microorganismos; poliaromaticos.

1 Directora de la Carrera de Ingeniería Ambiental en la Universidad Mayor Real y Pontificia de San Francisco Xavier de Chuquisaca, Sucre, Bolivia; rodriguez.apolonia@usfx.bo; https://orcid.org/0000-0001-9416-9787

2 Investigador Afiliado a la Carrera de Ingeniería Química, Universidad Mayor Real y Pontificia San Francisco Xavier de Chuquisaca, Sucre, Bolivia; zarate.sandra@usfx.bo, Docente de la Universidad Privada Domingo Savio, Sucre, Bolivia, su.sandra.zarate.v@upds.net.bo, https://orcid.org/0000-0003-2501-388X

3 Científica Titular del Instituto de Química Orgánica General, Consejo Superior de Investigaciones Científicas (CSIC), Madrid, España; agatha.bastida@csic.es; https://orcid.org/0000-0002-5141-9595

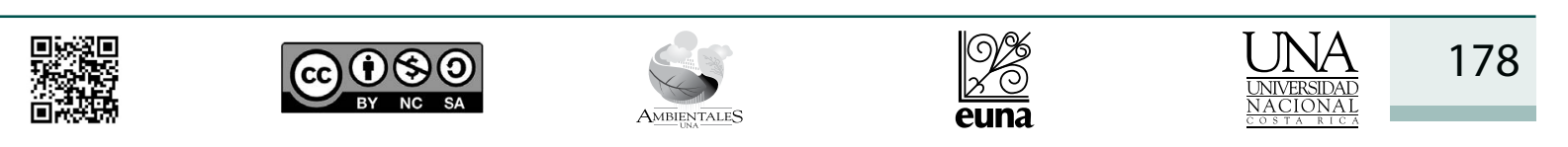




\section{Revista de CIENCIAS AMBIENTALES Tropical Journal of Environmental Sciences}

Revista de Ciencias Ambientales (Trop J Environ Sci) e-ISSN: 2215-3896

(Enero-Junio, 2022) . Vol 56(1): 178-208 DOI: https://doi.org/10.15359/rca.56-1.9 Open Access: www.revistas.una.ac.cr/ambientales e-mail: revista.ambientales@una.ac.cr Rodríguez-Gonzales A., Zárate-Villarroel S., Bastida-Codina A.

\begin{abstract}
[Introduction]: Bioremediation is a technology that uses microorganisms (bacteria, fungi, algae) or enzymes to biodegrade oil pollutants and derivatives and other pollutants that are present in soil, air, or water. In Latin America there is a high degree of pollution of its ecosystems, therefore, this technology is economically and environmentally viable to degrade these pollutants. Polycyclic aromatic hydrocarbons, such as asphaltenes and resins, are difficult to degrade, as well as polychlorinated aliphatics and biphenyls. [Objective]: It seeks to give an overview of recent publications on scientific research carried out regarding bioremediation methodologies for soils contaminated by oil and its derivatives. [Methodology]: An exhaustive search of the scientific literature of recent years was carried out, related to the proposed topic in bibliographic databases: Medline, Current Contents, PubMed, Google scholar, SciFinder, Scopus and in specialized journals: Chemosphere, Applied Microbiology, Biodegradation \& Biodeterior, American Society for Microbiology, Frontal Microbiology, Sci Total Environ. The keywords used were in Spanish or English. [Results]: Polyaromatic hydrocarbons can be biodegraded by bacterial consortia, such as phenanthrene (aromatic compound) which was biodegraded by 11 different bacterial strains (Sphingobium, Sphingomonas, Acidovorax, Alkaligenes, Actinobacteria, Burkholderia sp., Rhizobium sp., Pseudomonas sp., Pseudomonas sp., Stenotrophomonas and Sinorhizobium). In bioremediation, physicochemical variables such as $\mathrm{pH}$, temperature, oxygen, and humidity are considered important, as they are factors that influence the success of the treatment. [Conclusions]: With this bibliographic review, we seek to provide viable solutions to various hydrocarbon pollution problems in Latin American ecosystems.
\end{abstract}

Keywords: Metabolism; microorganisms; ecosystems; pollutants; polyaromatic

\title{
1. Introducción
}

La demanda de la sociedad mundial por el uso de petróleo y sus derivados tanto para ser usados en procesos industriales como a nivel de usuarios es cuantiosa. El poder usar estos recursos requiere que las empresas petroleras lleven a cabo actividades de exploración, explotación, refinación, industrialización, comercialización, distribución de gas por redes, transporte y almacenaje. Todo esto conlleva una alta contaminación de ecosistemas terrestres y acuáticos, debido al derrame de petróleo crudo y sus derivados. La mayor contaminación proviene del uso de este material tanto para vehículos como en la industria. Por otro lado, la mayoría de las emisiones producidas por estos compuestos puede representar riesgos irreversibles, como consecuencia de sus diferentes concentraciones depositadas en el agua o suelo. Además, por sus características de persistencia durante largos periodos de tiempo, así como por los cambios adversos producidos al entrar en contacto con la flora, fauna y con seres humanos, hace que el petróleo y sus derivados sean contaminantes altamente peligrosos.

La no degradación del petróleo y sus derivados se debe a que son compuestos muy hidrófobos (no polares), presentando una muy baja solubilidad en agua por lo que son nocivos para los organismos acuáticos y terrestres no permitiendo el crecimiento de plantas, debido a que los poros del suelo que contiene aire están saturados de estos contaminantes. Así, una herramienta muy útil para solucionar este problema es la biorremediación, la cual permite restaurar suelos o aguas contaminadas, siendo esta técnica una alternativa biotecnológica muy interesante. Dicha

\begin{tabular}{|c|c|c|c|c|c|}
\hline 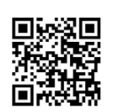 & (c) () (5) () & $\overbrace{\text { AMBENTILES }}$ & $\frac{\mid 0 \%}{\text { euna }}$ & $\frac{\text { UNA }}{\frac{\text { UNIVERSIDAD }}{\text { NACIONAL }}}$ & 179 \\
\hline
\end{tabular}




\section{Revista de CIENCIAS AMBIENTALES Tropical Journal of Environmental Sciences}

Revista de Ciencias Ambientales (Trop J Environ Sci)

e-ISSN: 2215-3896

(Enero-Junio, 2022) . Vol 56(1): 178-208

DOI: https://doi.org/10.15359/rca.56-1.9

Open Access: www.revistas.una.ac.cr/ambientales e-mail: revista.ambientales@una.ac.cr

Rodríguez-Gonzales A., Zárate-Villarroel S., Bastida-Codina A.

técnica utiliza microorganismos con capacidad de biodegradar hidrocarburos como fuente de energía para su crecimiento y desarrollo (Rakowska, 2020).

Investigaciones realizadas por Naciones Unidas sobre el efecto de la industria del petróleo en América Latina indican que este carburante es la principal materia prima que se produce y se exporta en esa región y, como consecuencia de la explotación de este recurso, se tienen evidencias fácticas de la contaminación ambiental y se tienen algunos ejemplos, en la amazonia ecuatoriana, colombiana, boliviana, peruana, los ecosistemas han sido impactados por grandes volúmenes de contaminantes hidrocarburíferos, cuyo resultado son los pasivos ambientales que son fuente de contaminación, actualmente están presentes, pasivos ambientales petroleros en el parque nacional Aguragüe en Bolivia (Fritz, 2020; Guevara, 2017), otro a orillas del lago Titicaca, Perú (Fritz, 2020), el derrame de Exón Valdez y otros incidentes que se encuentran en la literatura publicada (Lugo, 2017). En todos estos países latinoamericanos, y particularmente en los de mayor desarrollo, se presta cada vez mayor atención a los problemas de contaminación y su mitigación para la preservación del medio ambiente.

Una herramienta para solucionar este problema ambiental es el uso de microorganismos naturales para degradar o descomponer sustancias que son contaminantes y convertirlas en otras menos tóxicas o inocuas para el medio ambiente. Esta herramienta biotecnológica se llama biorremediación y es una tecnología emergente que utiliza organismos vivos (plantas, algas, hongos y bacterias) para absorber, degradar o transformar los contaminantes y retirarlos, inactivarlos o atenuar su efecto en el suelo, el agua y el aire (Vandera \& Koukkou, 2017). La técnica puede ser empleada para atacar contaminantes específicos del suelo, por ejemplo, en la degradación bacteriana de compuestos organoclorados o de hidrocarburos. Por otro lado, debido al incumplimiento de las Normas Sociales y Ambientales, impuestas por diferentes Gobiernos para el aprovechamiento sostenible de los recursos naturales (petróleo, gas), a menudo se conduce a eventos de deforestación que destruyen el hábitat de especies de plantas y animales, produciendo pérdidas de biodiversidad nativa de flora y fauna, que comprende el sustento de muchas comunidades indígenas (Hernández-Valencia, 2017). Durante muchos años se han producido en países de América latina numerosos derrames de petróleo que contaminan el medio ambiente, degradando el ecosistema y la salud, tanto en animales como en humanos, siendo la biorremediación una alternativa biotecnológica para resolver este problema (Azubuike, 2016). Es necesario abordar la problemática no resuelta, si existen investigaciones realizadas, se deben emplear esos conocimientos como estrategia de solución; sin embargo, varios Gobiernos latinoamericanos no abordan el problema al no ejercer cohesión para el cumplimiento de las normas ambientales por parte de las empresas que trabajan en la explotación de los hidrocarburos, existe una dependencia financiera de los ingresos económicos, generados por la venta de estos recursos y terminan aceptando a veces los altos costos ambientales ocasionados (Moyna Mendoza et al., 2020).

El petróleo crudo y sus derivados, compuestos por productos orgánicos de diferente composición y características químicas y físicas, es un combustible que puede estar en forma ligera,

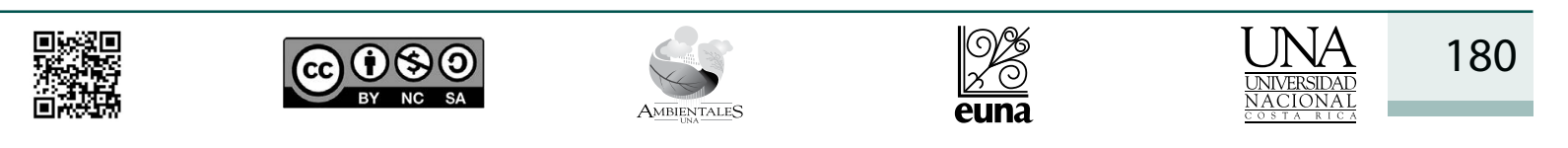




\section{Revista de CIENCIAS AMBIENTALES Tropical Journal of Environmental Sciences}

Revista de Ciencias Ambientales (Trop J Environ Sci)

e-ISSN: 2215-3896

(Enero-Junio, 2022) . Vol 56(1): 178-208

DOI: https://doi.org/10.15359/rca.56-1.9

Open Access: www.revistas.una.ac.cr/ambientales e-mail: revista.ambientales@una.ac.cr

Rodríguez-Gonzales A., Zárate-Villarroel S., Bastida-Codina A.

volátiles y pesados, compuesta de una mezcla compleja de hidrocarburos, muchos de estos tienen una composición química aproximada, además de carbono e hidrogeno, presentan azufre y nitrógeno en las siguientes proporciones: $84-87 \%$ carbono, $11-14 \%$ hidrogeno, $0-2 \%$ azufre y 0.2 \% nitrógeno, clasificándose en: hidrocarburos aromáticos policíclicos (HAPs), hidrocarburos saturados, asfaltenos y resinas (Viñas Canals, 2005). Estos compuestos son persistentes en el medio ambiente, debido a su compleja biodegradación, por lo que son potencialmente cancerígenos a causa de su alta bioacumulación en el organismo vivo (Sayed et al., 2021).

Los hidrocarburos aromáticos policíclicos (HAP) son compuestos que se obtienen principalmente de la combustión incompleta de materia orgánica, como el carbón, petróleo o gasolina. Se le considera contaminantes prioritarios, debido a su peligro intrínseco, ya que presentan una toxicidad aguda al ser teratogénicos, mutagénicos, cancerígenos (Romero Izquierdo, 2013) y recalcitrantes. Esta propiedad conduce a su bioacumulación en el tejido adiposo de los seres vivos; además, son capaces de ocasionar deterioro del material genético (genotoxicidad). Son comunes del petróleo crudo y son persistentes, ya que están conformados por más de 100 variedades de compuestos, que tienen dos o más anillos aromáticos unidos entre sí. Las agencias internacionales de investigaciones sobre el cáncer han descrito hasta $60 \mathrm{HAP}$. Entre estos grupos se encuentran el benzo(a) pireno carcinogénico para los humanos, y los compuestos de ciclopental $(a, d)$ pireno, dibenzo $(a, h)$ antraceno y dibenzo $(a, 1)$ pireno, los cuales fueron clasificados como probables carcinogénicos; mientras que el benz [j] aceantrileno, benz [a] antraceno $(\mathrm{BaA})$, benzo $[\mathrm{b}]$ fluoranteno $(\mathrm{BbF})$ y otros 12 compuestos de similares características químicas han sido clasificados como posibles carcinogénicos para humanos (Cuadro 1). La exposición durante corto o mediano plazo de este tipo de compuestos puede producir disfunción reproductiva y en las mujeres embarazadas pueden afectar al feto (Zhang et al., 2021).

Los HAP normalmente se encuentran en fase gaseosa o en forma de partículas móviles (PM) en las capas de la atmosfera terrestre. Los que se encuentran en fase gaseosa son los compuestos de bajo peso molecular que pueden presentar dos o tres anillos de carbono, mientras que los que contienen cuatro anillos de carbono con un peso molecular medio se suelen encuentran tanto en fase gaseosa como en forma de PM, debido a las condiciones ambientales. Por otro lado, los compuestos con cinco o seis anillos de carbono, cuyo peso molecular es alto, se encuentran en su mayoría en forma de PM. El diámetro de estas partículas es diferenciado, siendo más pequeños aquellos que recién fueron emitidos desde una fuente identificable y, por tanto, se mantienen en la atmosfera por largos periodos de tiempo hasta que ocurra la coagulación de las partículas y se produzca la deposición húmeda o seca, gracias a su propia velocidad de sedimentación (Zhang et al., 2021).

Los asfaltenos son compuestos sólidos y se obtienen a partir de materiales bituminosos o del petróleo crudo, utilizando disolventes de bajo peso molecular (n-pentano y el n-heptano) que son peligrosos para la salud y el medio ambiente, porque son químicamente estables, lo que implica que se encuentran en su estado de menor energía; por lo tanto, recalcitrantes, esta condición puede conducir a su bioacumulación en los seres vivos por deposición en el tejido adiposo.

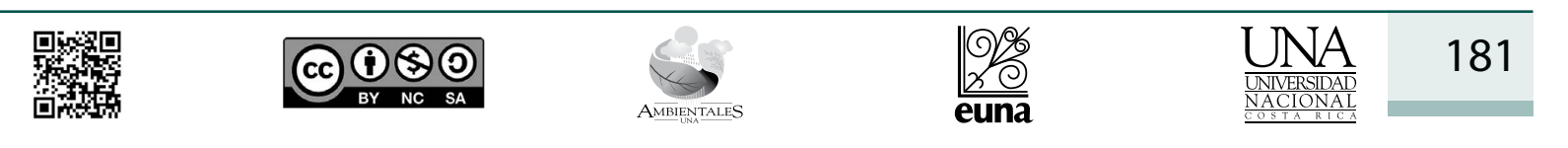




\section{Revista de CIENCIAS AMBIENTALES Tropical Journal of Environmental Sciences}

Revista de Ciencias Ambientales (Trop J Environ Sci) e-ISSN: 2215-3896 (Enero-Junio, 2022) . Vol 56(1): 178-208 DOI: https://doi.org/10.15359/rca.56-1.9 Open Access: www.revistas.una.ac.cr/ambientales e-mail: revista.ambientales@una.ac.cr Rodríguez-Gonzales A., Zárate-Villarroel S., Bastida-Codina A.

$\mathrm{Al}$ encontrarse los hidrocarburos poliaromáticos en el aire, agua y suelos, estos rápidamente son absorbidos por las partículas del suelo, por ser este recurso natural un sumidero natural de estos contaminantes. Los compuestos volátiles se depositan en la atmosfera terrestre, en los cuerpos de agua y en las plantas, mediante la deposición seca y húmeda, llegando finalmente a la cadena alimenticia; dando lugar a problemas de salud. Se ha demostrado en trabajos de investigación científicos, que un porcentaje alto en humanos presenta un riesgo de sufrir cáncer por la ingestión de alimentos contaminados con HAPs y aproximadamente un $2 \%$ es por la ruta de inhalación (Patel et al., 2020). Así mismo, por exposiciones prolongadas a estos hidrocarburos (HAP), pueden aparecer tumores en piel, pulmón, colon, esófago, páncreas, mamas y la vejiga.

La fototoxicidad de los hidrocarburos poliaromáticos, se debe a que la luz solar tiene componentes en la luz visible y ultravioleta (UVA, UVB), donde los HAP pueden absorber la UVB y, como consecuencia, se forman especies reactivas. Estas son las causantes de los daños en la membrana celular, en las proteínas y en el ácido nucleico de las células, lo que implica que la oxidación del ADN es mayor en presencia de luz que en la oscuridad (Patel et al., 2020).

Como una alternativa frente a la contaminación ambiental producida por los compuestos del petróleo, han sido desarrolladas diferentes tecnologías que incluyen tratamientos químicos, físicos y microbiológicos, para la restauración de áreas que han sufrido daños ambientales (Ławniczak, 2020). Los métodos físicos y químicos son los más caros y requieren intervenciones que incurren en altos gastos económicos. Sin embargo, la biorremediación microbiana es una alternativa beneficiosa para el medio ambiente y menos costosa económicamente (Patel et al., 2020).

Las técnicas desarrolladas para llevar a cabo la biorremediación microbiana pueden ser: agregación de microorganismos con capacidad de eliminar los contaminantes presentes en el medio ambiente; adición de oxígeno o nutrientes al suelo contaminado para estimular la actividad microbiana nativa y así propiciar la biodegradación de los contaminantes; y la atenuación natural por los microorganismos nativos del suelo (bacterias, hongos y levaduras) que degradan los contaminantes (Abasolo Pacheco \& Morante Carriel, 2019). De la literatura se desprende que el uso de las técnicas de biorremediación es más frecuente $(33 \%)$ frente a otras como el uso de biorreactores, o la fitorremediación/rizorremediación (22\%). Otros tratamientos menos comunes son: el compostaje con un $13 \%$, la de biopilas en un $4 \%$ y las técnicas de biorremediación enzimática o de vermirremediación del $2 \%$ (Patel et al., 2020).

El objetivo de este artículo de revisión es dar una visión global de las publicaciones de investigaciones científicas realizadas a lo largo del tiempo, con respecto a metodologías de biorremediación de suelos contaminados por petróleo y sus derivados en países latinoamericanos, diferentes tipo de tratamiento, ventajas y desventajas, cómo afectan los contaminantes en los ecosistemas y a la salud de los seres vivos, porcentajes de efectividad del tratamiento, tipos de bacterias, sus enzimas, así como los genes involucrados, y la necesidad de buscar métodos de biorremediación para mejorar la calidad de los ecosistemas contaminados latinoamericanos.

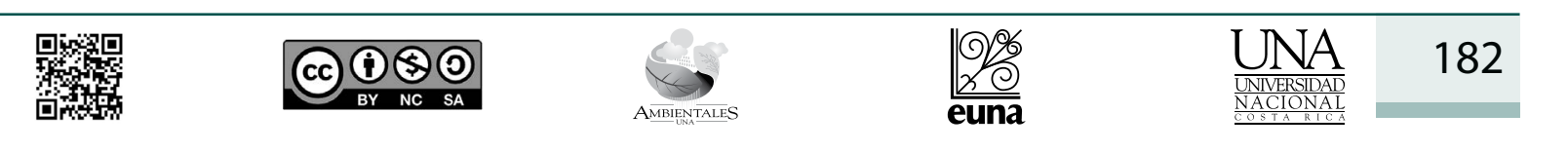




\section{Revista de CIENCIAS AMBIENTALES Tropical Journal of Environmental Sciences}

Revista de Ciencias Ambientales (Trop J Environ Sci) e-ISSN: 2215-3896

(Enero-Junio, 2022) . Vol 56(1): 178-208 DOI: https://doi.org/10.15359/rca.56-1.9 Open Access: www.revistas.una.ac.cr/ambientales e-mail: revista.ambientales@una.ac.cr

Rodríguez-Gonzales A., Zárate-Villarroel S., Bastida-Codina A.

\section{Metodología}

Para la presente revisión bibliográfica, se realizó la búsqueda exhaustiva de literatura científica relacionada con el tema propuesto en diferentes bases de datos bibliográficos como: Medline, Current Contents, PubMed, Google scholar, SciFinder, Scopus; así como en revistas especializadas del campo: Chemosphere, Applied Microbiology, Int Biodeterior Biodegradation, American Society for Microbiology, Front Microbiol y Sci Total Environ, además de Wikipedia. Para información más detallada, se consultaron libros del campo de investigación propuesto en este artículo tales como: Hydrocarbon Bioremediation, por Hinchee et al. (1991), Microbial ecotoxicology de Vandera y Koukkou (2017), Microbial Ecotoxicology: Bacterial Community Response to Hydrocarbon Contamination in Soils and Marine Sediments: A Critical Review of Case Studies por Watkinson y Morgan (1991), así como Biochemistry of microbial degradation de Ratledge (1994).

\section{Resultados}

\subsection{Impactos de los hidrocarburos en el medio ambiente y la salud pública}

Para comprender los impactos de los hidrocarburos en el medio ambiente y en la salud, es importante conocer algunas de las propiedades fisicoquímicas de aquellos compuestos considerados peligrosos en el (Cuadro 1) se muestran algunos ejemplos tomando en cuenta propiedades como: punto de ebullición (P.E.), de fusión (O.F), de congelación (P.C) y peso molecular (P.M.).

Cuadro 1. Resumen de propiedades fisicoquímicas de componentes de hidrocarburos, aromáticos, alcanos de cadena lineal y ramificada.

Table 1. Summary of physicochemical properties of components of hydrocarbons, aromatics, straight and branched chain alkanes.

\begin{tabular}{|c|c|c|c|}
\hline Hidrocarburo & Formula Química & Características fisicoquímicas & Riesgos para la salud \\
\hline Butano & $\mathrm{C}_{4} \mathrm{H}_{10}$ & $\begin{array}{l}\text { P.E. }-274.15^{\circ} \mathrm{C} \text {, } \\
\text { P.F. }-138^{\circ} \mathrm{C} \text {, } \\
\text { P.C }-80^{\circ} \mathrm{C} \text {, } \\
\text { P.M. } 58 \mathrm{~g} / \mathrm{mol}\end{array}$ & $\begin{array}{l}\text { Cuando es inhalado, puede causar } \\
\text { asfixia, y congelación en contacto } \\
\text { con la piel. }\end{array}$ \\
\hline Benceno & $\mathrm{C}_{6} \mathrm{H}_{6}$ & $\begin{array}{l}\text { P.M. } 78.11 \mathrm{~g} / \mathrm{mol} \\
\text { P.F. } 80.05^{\circ} \mathrm{C} \\
\text { P.C. }-11.15^{\circ} \mathrm{C}\end{array}$ & $\begin{array}{l}\text { Cancerígeno, si se inhala del aire o } \\
\text { de alimentos y bebidas contaminadas } \\
\text { depositándose en el sistema } \\
\text { gastrointestinal. }\end{array}$ \\
\hline Fenol & $\mathrm{C}_{6} \mathrm{H}_{6} \mathrm{O}$ & $\begin{array}{l}\text { P.M. } 94.11 \mathrm{~g} / \mathrm{mol} \\
\text { P.F. } 181.85^{\circ} \mathrm{C} \\
\text { P.C } 79^{\circ} \mathrm{C}\end{array}$ & Irritación de las vías respiratorias. \\
\hline Etil-benceno & $\mathrm{C}_{8} \mathrm{H}_{10}$ & P.M. 106.17 g/mol, P.F. $136.2^{\circ} \mathrm{C}$ & $\begin{array}{l}\text { Fácilmente absorbido por la piel y los } \\
\text { pulmones. }\end{array}$ \\
\hline 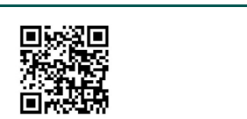 & & euna & $\frac{\text { UNA }}{\frac{\text { MNIVERSIDAD }}{\text { UACIONAL }}}$ \\
\hline
\end{tabular}




\section{Revista de

(Enero-Junio, 2022). Vol 56(1): 178-208

DOI: https://doi.org/10.15359/rca.56-1.9

Open Access: www.revistas.una.ac.cr/ambientales e-mail: revista.ambientales@una.ac.cr

Rodríguez-Gonzales A., Zárate-Villarroel S., Bastida-Codina A.

\begin{tabular}{|c|c|c|c|}
\hline Hidrocarburo & Formula Química & Características fisicoquímicas & Riesgos para la salud \\
\hline Naftaleno & $\mathrm{C}_{10} \mathrm{H}_{8}$ & $\begin{array}{l}\text { P.M. } 128.17 \mathrm{~g} / \mathrm{mol} . \text {, } \\
\text { P.E. } 218^{\circ} \mathrm{C} \\
\text { P.C. } 82.85^{\circ} \mathrm{C}\end{array}$ & $\begin{array}{l}\text { Dolor de cabeza, náuseas, vómitos e } \\
\text { irritación en la piel. }\end{array}$ \\
\hline Fenantreno & $\mathrm{C}_{14} \mathrm{H}_{10}$ & $\begin{array}{l}\text { P.M. } 178.23 \mathrm{~g} / \mathrm{mol} \\
\text { P.E. } 336^{\circ} \mathrm{C} \\
\text { P.C. } 171^{\circ} \mathrm{C} \\
\text { P.F. } 97-100^{\circ} \mathrm{C}\end{array}$ & $\begin{array}{l}\text { Dañino cuando se ingiere y toxico } \\
\text { para la vida acuática }\end{array}$ \\
\hline Antraceno & $\mathrm{C}_{14} \mathrm{C}_{10}$ & $\begin{array}{l}\text { P.M. } 178.23 \mathrm{~g} / \mathrm{mol} \\
\text { P.E. } 216^{\circ} \mathrm{C} \\
\text { B.P } 340^{\circ} \mathrm{C}\end{array}$ & $\begin{array}{l}\text { La inhalación causa tos, falta de } \\
\text { respiración, dolor de garganta. }\end{array}$ \\
\hline Pireno & $\mathrm{C}_{16} \mathrm{H}_{10}$ & $\begin{array}{l}\text { P.M. } 202.26 \mathrm{~g} / \mathrm{mol} \\
\text { P.E. } 145-148^{\circ} \mathrm{C} \\
\text { P.F. } 404^{\circ} \mathrm{C}\end{array}$ & $\begin{array}{l}\text { Tóxico e irritante para los riñones y } \\
\text { el hígado. }\end{array}$ \\
\hline Fluoranteno & $\mathrm{C}_{16} \mathrm{H}_{10}$ & $\begin{array}{l}\text { P.M. } 202.25 \mathrm{~g} / \mathrm{mol} \\
\text { P.F. } 111^{\circ} \mathrm{C} \\
\text { P.E. } 384^{\circ} \mathrm{C}\end{array}$ & $\begin{array}{l}\text { Vía oral toxicidad aguda e irritación } \\
\text { ocular. }\end{array}$ \\
\hline Fluoreno & $\mathrm{C}_{13} \mathrm{H}_{10}$ & $\begin{array}{l}\text { P.M. } 166 \mathrm{~g} / \mathrm{mol} \\
\text { P.E. } 298^{\circ} \mathrm{C} \\
\text { F. } 114^{\circ} \mathrm{C} \\
\text { P.C. } \leq 21^{\circ} \mathrm{C}\end{array}$ & $\begin{array}{l}\text { Puede causar cáncer. } \\
\text { Toxico para peces }\end{array}$ \\
\hline Benzo-pireno & $\mathrm{C}_{20} \mathrm{H}_{12}$ & $\begin{array}{l}\text { P.M. } 252.31 \mathrm{~g} / \mathrm{mol} \\
\text { P.F. } 179^{\circ} \mathrm{C} \\
\text { P.E. } 495^{\circ} \mathrm{C}\end{array}$ & $\begin{array}{l}\text { Cáncer de pulmón, vejiga, labio, } \\
\text { boca, laringe, melanoma y sistema } \\
\text { linfático. }\end{array}$ \\
\hline Ace-nafteno & $\mathrm{C}_{12} \mathrm{H}_{10}$ & $\begin{array}{l}\text { P.M. } 154.2 \mathrm{~g} / \mathrm{mol} \\
\text { P. F. } 95^{\circ} \mathrm{C} \\
\text { P. E. } 279^{\circ} \mathrm{C}\end{array}$ & Irritación en la piel \\
\hline Ace-naftileno & $\mathrm{C}_{12} \mathrm{H}_{8}$ & $\begin{array}{l}\text { P.M. } 152.19 \mathrm{~g} / \mathrm{mol} \\
\text { P.F. } 96.7^{\circ} \mathrm{C} \\
\text { P.E. } 40{ }^{\circ} \mathrm{C} \\
\text { Flash P. }<0{ }^{\circ} \mathrm{C}\end{array}$ & $\begin{array}{l}\text { Cáncer, toxicidad aguda en contacto } \\
\text { con la piel, } \\
\text { irritación en la piel y los ojos. }\end{array}$ \\
\hline Criseno & $\mathrm{C}_{18} \mathrm{H}_{12}$ & $\begin{array}{l}\text { P.M. } 228.29 \mathrm{~g} / \mathrm{mol} \\
\text { P.F. } 254^{\circ} \mathrm{C} \\
\text { P.E. } 448^{\circ} \mathrm{C}\end{array}$ & Irrita la piel, ojos, garganta. \\
\hline
\end{tabular}

Enciclopedia de salud y seguridad en el trabajo (s.f.). Recuperado el 1 de noviembre de 2021, de: (https://www.insst. es/documents/94886/162038/6.+Hidrocarburos+arom\%C3\%A1 ticos-+Hidrocarburos+arom\%C3\%A1ticos+halogenados- +Hidrocarburos+poli arom\%C3\%Alticos++-+Isocianatos+-+Cetonas).

\begin{tabular}{|c|c|c|}
\hline 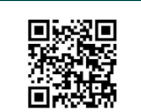 & (c) () & 184 \\
\hline
\end{tabular}




\section{Revista de CIENCIAS AMBIENTALES Tropical Journal of Environmental Sciences}

Revista de Ciencias Ambientales (Trop J Environ Sci) e-ISSN: 2215-3896

(Enero-Junio, 2022) . Vol 56(1): 178-208

DOI: https://doi.org/10.15359/rca.56-1.9

Open Access: www.revistas.una.ac.cr/ambientales e-mail: revista.ambientales@una.ac.cr

Rodríguez-Gonzales A., Zárate-Villarroel S., Bastida-Codina A.

\section{Características de compuestos presentes en el medio ambiente}

4.1 Alcanos: $C_{1}-C_{4}$ a temperatura ambiente se encuentran en estado gaseoso, $C_{5}-C_{15}$ estado líquido y en estado sólido a partir de $\mathrm{C}_{16}$ (Arrieta et al. 2012; Heiss et al. (2005). Los alcanos lineales son más biodegradables y los ramificados menos biodegradables, los alcanos con de 5 a 10 carbonos a altas concentraciones inhiben su degradación. Este grupo de alcanos es la fracción más volátil del crudo y susceptible a pérdidas abióticas. La exposición prolongada, puede causar dermatitis o cáncer de piel (Coll Almela, 2021; Hu et al., 2020).

4.2 Hidrocarburos monoaromáticos: son altamente insaturados junto con otros compuestos como alquenos, alquinos y derivados de benceno, que son insolubles en agua. Los compuestos de benceno alquilados (tolueno y xilenos) forman la familia BTEX (benceno, tolueno, etilbenceno y xileno) considerados muy tóxicos. El benceno en grandes cantidades en el ambiente ingresa al cuerpo por inhalación, o por consumo de alimentos o bebidas contaminadas, depositándose en el torrente sanguíneo con lo que se almacena en la médula ósea y los tejidos grasos (Hidalgo et al., 2020).

4.3 Hidrocarburos poliaromáticos (HAP): los compuestos principales del petróleo crudo son di-aromáticos como el naftaleno y sus grupos alquilados; entre los poliaromáticos con 3 anillos tenemos al antraceno, fenantreno, fluoreno y sus derivados alquilados; el fluoranteno, criseno, pireno, y benzo(a)pireno pertenecen a hidrocarburos con más de tres anillos (Hidalgo et al., 2020). El peligro intrínseco de los HAPs ha sido investigado por varias instituciones ambientales, debido a los riesgos de toxicidad aguda, mutagénica, teratogénica y carcinogénica. Estos tienen características de bioacumulación en organismos y su biodegradación es muy lenta, debido a su alto peso molecular y a la hidrofobicidad e insolubilidad en agua (Patel et al., 2020; Feng et al., 2021).

El naftaleno y fenantreno han sido ampliamente investigados utilizando procesos de biorremediación con numerosas cepas de bacterias aerobias mayormente, así mismo se han investigado las rutas metabólicas de biodegradación que se encuentran en los diversos artículos científicos publicados. Existen estrategias para degradar a los HAPs, de acuerdo con la metodología de la investigación a seguir; en la situación de que sea por el método aerobio, juega un rol muy importante el oxígeno, porque es aceptor de electrones, pero también sirve de co-sustrato para la escisión oxigenolítica e hidroxilación del anillo aromático. Mientras que la degradación anaerobia es completamente diferente porque utilizan aceptores de electrones para los iones sulfato o nitratos. En la biodegradación aeróbica se involucran las enzimas dioxigenasas que son enzimas reductasas y las proteínas ferredoxinas, que son proteínas hierro-azufre que intervienen en el transporte de electrones en reacciones del metabolismo. Estas proteínas presentan subunidades terminales que actúan como enzimas monooxigenasa o dioxigenasa siendo por lo general el primer paso la degradación bacteriana llamada hidroxilación (Ghosal et al., 2016).

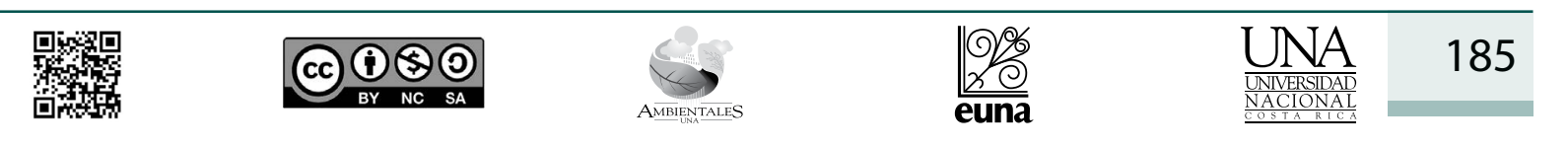




\section{Revista de CIENCIAS AMBIENTALES Tropical Journal of Environmental Sciences}

Revista de Ciencias Ambientales (Trop J Environ Sci) e-ISSN: 2215-3896 (Enero-Junio, 2022) . Vol 56(1): 178-208 DOI: https://doi.org/10.15359/rca.56-1.9 Open Access: www.revistas.una.ac.cr/ambientales e-mail: revista.ambientales@una.ac.cr

Rodríguez-Gonzales A., Zárate-Villarroel S., Bastida-Codina A.

Para que se desarrollen los mecanismos de biodegradación aeróbica, se necesita de la presencia del oxígeno molecular, facilitando así que la dioxigenasa produzca la oxidación de los diferentes anillos de los hidrocarburos. Por ello, como resultado de esa reacción se obtendrá un bi-producto enzimático multicomponente llamado cis-dihidrioles. Posteriormente, son divididos estos componentes por las dioxigenasas en anillos intradiol o extradiol, para unirse mediante una vía de orto-escisión o meta-escisión, que conduce a la formación de productos intermediarios centrales como el protocatecuato y catecoles, que son los precursores del ciclo del ácido tricarboxilico (Vandera et al., 2017).

Existen numerosas bacterias aerobias y anaerobias capaces de metabolizar a estos compuestos como los géneros Xanthomonas, Comamonas, Burkholderia, etc., tal como se muestra en el Cuadro 2, los cuales tienen características específicas para biodegradar a los HAPs. Por otro lado, un consorcio bacteriano puede lograr la biodegradación completa, gracias al potencial genético de estas y a los factores ambientales (Figura 1) (Vandera \& Koukkou, 2017).

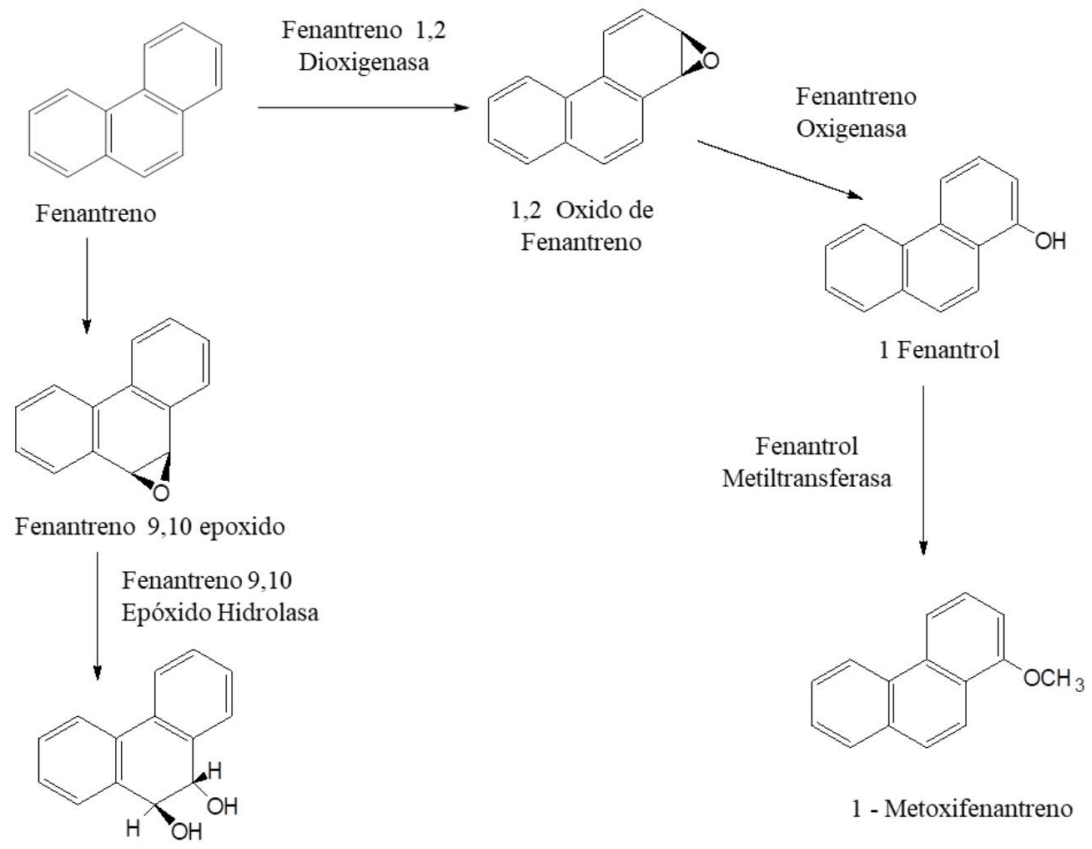

Trans 9,10 dihidrodiol Fenantreno

Figura 1. Ruta de degradación de fenantreno por bacterias (Vandera \& Koukkou, 2017)

Figure 1. Pathway of phenanthrene degradation by bacteria (Vandera \& Koukkou, 2017)

\begin{tabular}{|c|c|c|c|c|c|}
\hline 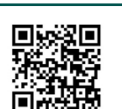 & (c) (i) (\&) (2) & 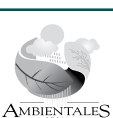 & $\frac{O \mathscr{O} 6}{20}$ & 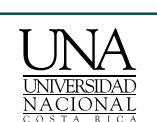 & 186 \\
\hline
\end{tabular}




\section{Revista de CIENCIAS AMBIENTALES Tropical Journal of Environmental Sciences}

Revista de Ciencias Ambientales (Trop J Environ Sci)

e-ISSN: 2215-3896

(Enero-Junio, 2022) . Vol 56(1): 178-208

DOI: https://doi.org/10.15359/rca.56-1.9

Open Access: www.revistas.una.ac.cr/ambientales

e-mail: revista.ambientales@una.ac.cr

Rodríguez-Gonzales A., Zárate-Villarroel S., Bastida-Codina A.

\subsection{Biorremediación de hidrocarburos en suelo y agua}

Una característica común de los hidrocarburos es su biodegradación de forma aerobia y anaerobia. Sin embargo, la tasa de biodegradación aerobia depende de la complejidad de la molécula contaminante y de la disponibilidad de aceptores de electrones (Hidalgo et al., 2020). Además, dicha biorremediación puede llevarse a cabo en condiciones in situ o ex situ.

a) ex situ, consiste en excavar el suelo contaminado y transportarlo a un sitio que ha sido preparado para la regeneración, en el que se realiza un movimiento constante para oxigenar y así facilitar la degradación, transformación e inmovilización de los contaminantes, a través de reacciones bióticas y abióticas, este método es amigable con el medio ambiente, porque utiliza una amplia variedad de microorganismos. Este método es capaz de biodegradar componentes del petróleo, reducir la toxicidad de los componentes gracias a la acción de enzimas presentes en los microorganismos asimilándolas en su biomasa microbiana e incorporándolos en sus procesos metabólicos, y convirtiendo los derivados de hidrocarburos complejos en dióxido de carbono y agua en condiciones aeróbicas. Este tipo de biorremediación logra una oxidación completa llamada mineralización de los contaminantes produciendo una biotransformación de compuestos orgánicos complejos a simples, y en una última etapa con lo que se produce una reducción de estos a menos tóxicos (Hidalgo et al., 2020).

b) in situ se produce por atenuación natural y consiste en degradar naturalmente a los contaminantes del suelo gracias a la acción de varios factores ambientales como la humedad, tipo de contaminante, $\mathrm{pH}$, materia orgánica, presencia de microorganismos autóctonos y otros factores por periodos de tiempo largos. También puede tener lugar por bioventilación aeróbica, la cual consiste en introducir oxígeno en el suelo, debido a las bajas concentraciones de este elemento, para así biodegradar aeróbicamente los contaminantes. Otra alternativa es la bioventilación cometabólica, que es muy similar a la bioventilación aeróbica, consistiendo en agregar un sustrato orgánico apropiado al suelo. Por último, cabe mencionar la bioventilación anaeróbica que consiste en inyectar un donante de electrones y nitrógeno en lugar de aire, de esta forma se generan condiciones anaeróbicas en el suelo contaminado (Ocampo Hernández, 2021).

También hay que mencionar la degradación de contaminantes en suelos por el proceso conocido como "compostaje" que consiste en el uso de microorganismos que degradan contaminantes a una temperatura de $40{ }^{\circ} \mathrm{C}-50^{\circ} \mathrm{C}$, de acuerdo con la técnica establecida (Ocampo Hernández, 2021; Patel et al., 2020).

\section{Microorganismos con la capacidad de biorremediar sitios contaminados por hidrocarburos}

La biodegradación del petróleo y sus derivados involucra desafíos para los microorganismos; ya que son mezclas complejas. La degradación de hidrocarburos se lleva a cabo principalmente por bacterias, seguidas por hongos, levaduras y algas entre otros. Los hidrocarburos de bajo peso molecular son tóxicos al ser líquidos actuando como disolventes sobre las membranas

\begin{tabular}{|c|c|c|c|c|c|}
\hline 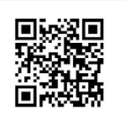 & (c) (i) () () & $\overbrace{\text { AMBENTILES }}$ & $\frac{1 \% \%}{\text { euna }}$ & 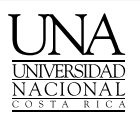 & 187 \\
\hline
\end{tabular}




\section{Revista de CIENCIAS AMBIENTALES Tropical Journal of Environmental Sciences}

Revista de Ciencias Ambientales (Trop J Environ Sci) e-ISSN: 2215-3896 (Enero-Junio, 2022) . Vol 56(1): 178-208 DOI: https://doi.org/10.15359/rca.56-1.9 Open Access: www.revistas.una.ac.cr/ambientales e-mail: revista.ambientales@una.ac.cr

Rodríguez-Gonzales A., Zárate-Villarroel S., Bastida-Codina A.

celulares de las células (las propiedades físicas de estos compuestos también afectan en la biodegradación, ver Cuadro 2). Debido a esto, los microorganismos han tenido que desarrollar una serie de adaptaciones, como su modificación de las vías metabólicas para ser capaces de utilizar hidrocarburos como sustratos. Han sido investigadas una gran variedad de bacterias con la capacidad de biodegradar diferentes tipos de hidrocarburos, contaminantes presentes en varios componentes ambientales y dicha biodegradación se lleva a cabo en condiciones aeróbicas o anaeróbicas, dependiendo del género de bacterias usada, ver (Figura 2) (lmela, 2020).

El mecanismo de los microorganismos para la degradación de los contaminantes consiste en convertir las moléculas de HAPs en compuestos solubles como son $\mathrm{CO}_{2}, \mathrm{O}_{2} \mathrm{y} \mathrm{H}_{2} \mathrm{O}$, los cuales responden a una biodegradación aeróbica. Los microorganismos son capaces de oxidar el contaminante mediante el uso de enzimas oxigenasas y peroxidasas, que son responsables de la alimentación de oxígeno al hidrocarburo (Figura 1) (Hidalgo et al., 2020).

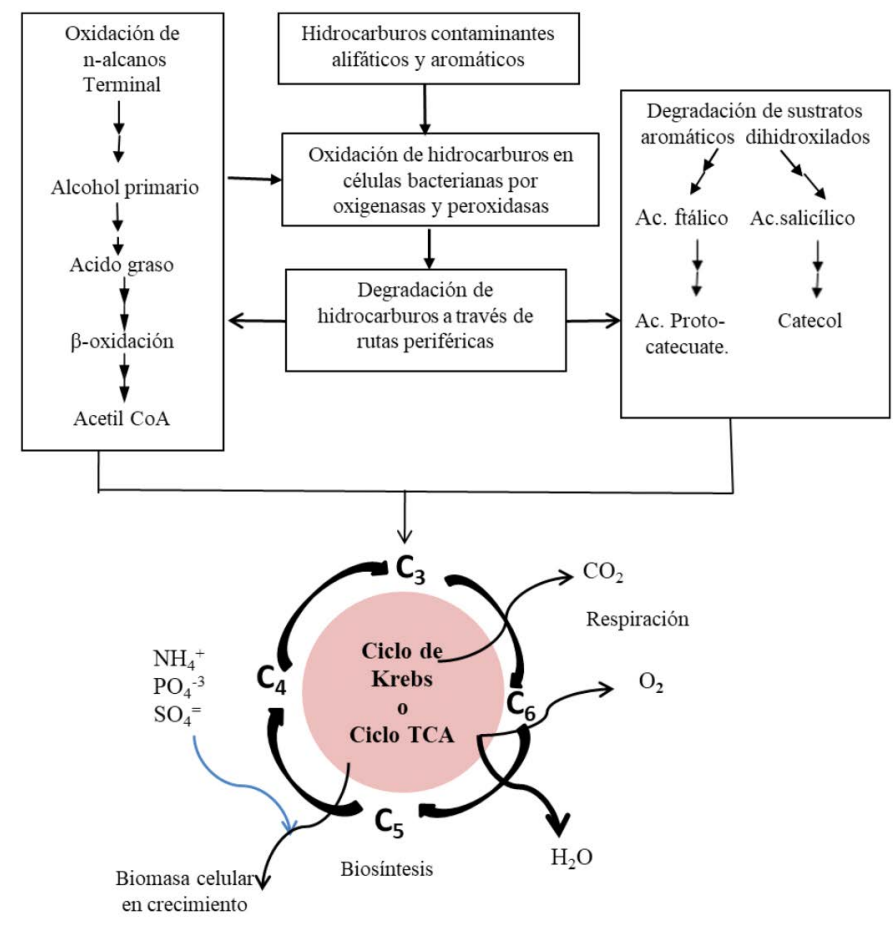

Figura 2. Principios generales de la degradación microbiana aeróbica de hidrocarburos aromáticos y alifáticos (Vandera \& Koukkou, 2017).

Figure 2. General principles of aerobic microbial degradation of aromatic and aliphatic hydrocarbons (Vandera \& Koukkou, 2017).

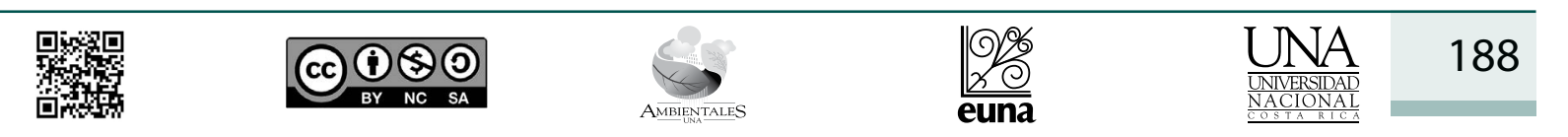




\section{Revista de CIENCIAS AMBIENTALES Tropical Journal of Environmental Sciences}

Revista de Ciencias Ambientales (Trop J Environ Sci)

e-ISSN: 2215-3896

(Enero-Junio, 2022) . Vol 56(1): 178-208

DOI: https://doi.org/10.15359/rca.56-1.9

Open Access: www.revistas.una.ac.cr/ambientales e-mail: revista.ambientales@una.ac.cr

Rodríguez-Gonzales A., Zárate-Villarroel S., Bastida-Codina A.

El petróleo crudo contiene mezclas de compuestos de hidrocarburos aromáticos y alifáticos que constituyen contaminantes del suelo y otros componentes ambientales. Se conoce que los compuestos aromáticos son más resistentes a la oxidación incluso con los oxidantes más potentes, debido a su estructura química que es muy estable. Sin embargo, los microorganismos poseen enzimas de tipo peroxidasas y oxigenasas que favorecen la oxidación, facilitando así la degradación de hidrocarburos aromáticos por rutas periféricas, siguiendo mecanismos que dependen de la naturaleza del hidrocarburo. Estas rutas generalmente culminan en estructuras de tipo catecol, en donde, siguiendo los procesos en el ciclo de Krebs, estas moléculas se reducen en estructuras inofensivas (Ghosal et al., 2016). Con respecto a la degradación de los n-alcanos, los carbonos terminales se oxidan sucesivamente a alcohol primario, aldehído y ácido graso, que tras una B-oxidación, se obtiene Acetil Co-enzima A, que luego se incorpora al ciclo de Krebs. Es suficiente que se hayan degradado en moléculas polares más pequeñas, estas son solubles en agua y, por lo tanto, ya no contaminan (Vandera \& Koukkou, 2017).

\subsection{Biodiversidad microbiana reportada en biorremediación de hidrocarburos en suelos por los métodos in situ y ex situ}

La investigación de biorremediación se ha llevado a cabo en suelos contaminados por hidrocarburos poliaromáticos. A continuación, se reportan los microorganismos capaces de degradar diferentes hidrocarburos, como fenantreno y antraceno, presentes en la mayoría de los suelos. El fenantreno se trató por el método in situ y las bacterias que se reportaron como biodegradadoras fueron Sphingomonas paucimobilis EPA 505, Sphingobium yanoikuyae B1 (Zhao et al., 2017), Sphingomonas paucimobilis NBRC 13935 (Zhao et al., 2017), logrando un porcentaje de biodegradación de este compuesto en un rango de $65 \%$ - 96.3\%, mientras que el porcentaje de biorremediación para Acidovorax carolinensis NA3 (Singleton et al., 2018) y Alcaligenes faecalis FK2 DSM 30030 fueron del $90 \%$ y 95 \% respectivamente. Para los microorganismos Brevundimonas, Actinobacteria, Burkholderia sp. BB26, Burkholderia sp. BB24 y Rhizobium sp. BY8, las investigaciones mostraron un porcentaje de biorremediación del $80 \%$. Las bacterias Rhizobium paknamense, Pseudomonas sp. Stenotrophomonas han sido ampliamente estudiadas, logrando resultados de biorremediación en los porcentajes de $99 \%, 98 \%$ - $99 \%$, $95 \%$ - $99 \%$, respectivamente; en los artículos revisados se encuentra poca información respecto a los genes de algunas bacterias que realizan biorremediación, ver el (Cuadro 2), solamente se tienen datos de los porcentajes de biorremediación de algunas bacterias en rangos del 65 \% - 99 \% (Arulazhagan et al., 2016; Hidalgo et al., 2020).

La degradación del antraceno tiene lugar por la presencia de tres géneros de bacterias, todas son del género Actinobacterias y se usan por el método ex situ o in situ. Cuando se utilizó $S$. paucimobilis EPA 505, se obtuvo una biodegradación del 93,3 \%, por el método ex situ y cuando se usó Sphingomonas sp. BA2 por el método in situ (Ruan et al., 2018) se obtuvieron resultados bajos de biodegradación, solo de un 26 \% (Hidalgo et al., 2020).

\begin{tabular}{|c|c|c|c|c|c|}
\hline 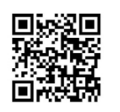 & 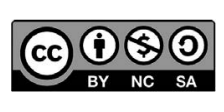 & $\overbrace{\text { AMBENTALIES }}$ & $\frac{1 \%}{2 \%}$ & $\frac{\text { UNA }}{\frac{\text { UNVERSIDAD }}{\text { NACIONAL }}}$ & 189 \\
\hline
\end{tabular}




\section{Revista de CIENCIAS AMBIENTALES

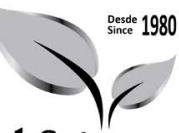 Tropical Journal of Environmental Sciences}

Revista de Ciencias Ambientales (Trop J Environ Sci) e-ISSN: $2215-3896$

(Enero-Junio, 2022) . Vol 56(1): 178-208

DOI: https://doi.org/10.15359/rca.56-1.9

Open Access: www.revistas.una.ac.cr/ambientales e-mail: revista.ambientales@una.ac.cr

Rodríguez-Gonzales A., Zárate-Villarroel S., Bastida-Codina A.

Cuadro 2. Bacterias reportadas en biorremediación de suelos y agua contaminados con hidrocarburos.

Table 2. Bacteria reported in bioremediation of soils and water contaminated with hydrocarbons.

\begin{tabular}{|c|c|c|c|c|}
\hline Contaminantes & Bacteria biorremediadora & $\begin{array}{l}\text { Medios de vida } \\
\text { y/o material } \\
\text { contaminado }\end{array}$ & $\begin{array}{l}\text { Porcentaje de } \\
\text { biorremediación } \\
\text { y tipo de } \\
\text { tratamiento }\end{array}$ & Referencias \\
\hline \multirow[t]{12}{*}{ Fenantreno } & $\begin{array}{l}\text { Sphingomonas paucimobilis EPA } \\
505\end{array}$ & Suelo & $\begin{array}{l}\text { in situ } \\
65 \%-96.3 \%\end{array}$ & Zhao et al. (2017) \\
\hline & Sphingobium yanoikuyae B1 & Suelo & $90 \%-95 \%$ & Schuler et al. (2009) \\
\hline & Acidovorax carolinensis NA3 & suelo & $\begin{array}{l}\text { in situ } \\
84 \%-95 \% \\
96 \%-99 \%\end{array}$ & Singleton et al. (2018) \\
\hline & $\begin{array}{l}\text { Alcaligenes faecalis FK2 (DSM } \\
\text { 30030) Brevundimonas }\end{array}$ & Suelo & $\begin{array}{l}\text { in situ } \\
90 \%-95 \%\end{array}$ & $\begin{array}{l}\text { Wong-Villarreal et al. } \\
\text { (2017) }\end{array}$ \\
\hline & Actinobacteria & Suelo & $\begin{array}{l}\text { ex situ } \\
9 \%\end{array}$ & (Ding et al., 2012) \\
\hline & Burkholderia sp. BB26 & Suelo & $\begin{array}{l}\text { in situ } \\
65 \%-78.5 \%\end{array}$ & $\begin{array}{l}\text { Wong-Villarreal et al. } \\
\text { (2017) }\end{array}$ \\
\hline & Burkholderia sp. BB24 & Suelo & $\begin{array}{l}\text { in situ } \\
68.5 \%\end{array}$ & \\
\hline & Rhizobium sp. BY8 & Suelo & $\begin{array}{l}\text { in situ } \\
99 \%\end{array}$ & \\
\hline & Rhizobium pakna-mense & Suelo & $\begin{array}{l}\text { in situ } \\
99 \%\end{array}$ & \\
\hline & Pseudomonas sp. & $\mathrm{nr}$ & $\begin{array}{l}\text { ex situ } \\
98 \%-99 \%\end{array}$ & (Milic et al., 2009) \\
\hline & Stenotrophomonas & $\mathrm{nr}$ & $\begin{array}{l}\text { ex situ } \\
95 \%-99 \%\end{array}$ & Zanaroli et al. (2010) \\
\hline & Sinorhizobium sp. C4 & $\mathrm{nr}$ & ex situ & (Keum et al., 2008) \\
\hline \multirow[t]{6}{*}{ Fluoreno } & $\begin{array}{l}\text { Sphingomonas paucimobilis EPA } \\
505\end{array}$ & Suelo & $\begin{array}{l}\text { ex situ } \\
95.1 \%\end{array}$ & (Desai et al., 2008) \\
\hline & Sphingobium yanoikuyae B1 & Suelo & $\begin{array}{l}\text { Rendimiento } \\
\text { In situ } \\
>98 \%\end{array}$ & Schuler et al. (2009) \\
\hline & $\begin{array}{l}\text { Sphingomonas paucimobilis NBRC } \\
13935 .\end{array}$ & Suelo & $\mathrm{n} / \mathrm{d}$ & (Viñas Canals, 2005) \\
\hline & Actinobacteria & Suelo & $\begin{array}{l}84 \%-95 \% \\
96 \%-99 \%\end{array}$ & Mutnuri et al. (2005) \\
\hline & Mycobacterium sp. & Suelo & Sin dato & $\begin{array}{l}\text { (Vandera \& Koukkou, } \\
\text { 2017) }\end{array}$ \\
\hline & Janibacter sp. strain $Y Y-1$ & Suelo & Sin dato & (Yamazoe et al., 2004) \\
\hline
\end{tabular}

\begin{tabular}{|c|c|c|}
\hline 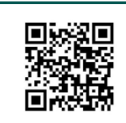 & 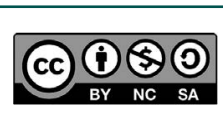 & 190 \\
\hline
\end{tabular}




\section{Revista de Desce 1980 CIENCIAS AMBIENTALES Tropical Journal of Environmental Sciences}

Revista de Ciencias Ambientales (Trop J Environ Sci) e-ISSN: 2215-3896 (Enero-Junio, 2022) . Vol 56(1): 178-208 DOI: https://doi.org/10.15359/rca.56-1.9 Open Access: www.revistas.una.ac.cr/ambientales e-mail: revista.ambientales@una.ac.cr Rodríguez-Gonzales A., Zárate-Villarroel S., Bastida-Codina A.

\begin{tabular}{|c|c|c|c|c|}
\hline Contaminantes & Bacteria biorremediadora & $\begin{array}{l}\text { Medios de vida } \\
\text { y/o material } \\
\text { contaminado }\end{array}$ & $\begin{array}{l}\text { Porcentaje de } \\
\text { biorremediación } \\
\text { y tipo de } \\
\text { tratamiento }\end{array}$ & Referencias \\
\hline \multirow{4}{*}{$\begin{array}{l}\text { Acenafteno y } \\
\text { Acenaftaleno }\end{array}$} & Sphingobium yanoikuyae B1 & & ex situ & Schuler et al. (2009) \\
\hline & & & $28.7 \%$ & \\
\hline & $\begin{array}{l}\text { Sphingomonas paucimobilis NBRC } \\
13935\end{array}$ & Suelo & $\begin{array}{l}\text { ex situ } \\
89.3 \%\end{array}$ & (Viñas Canals, 2005) \\
\hline & Sphingomonas sp. strain A4 & Suelo & ex situ & Kouzuma et al. (2006) \\
\hline \multirow[t]{4}{*}{ Naftaleno } & $\begin{array}{l}\text { Sphingomonas Paucimobilis EPA } \\
505\end{array}$ & Suelo & $\begin{array}{l}\text { ex situ } \\
96.3 \%\end{array}$ & Desai et al. (2008) \\
\hline & $\begin{array}{l}\text { Sphingomonas Paucimobilis NBRC } \\
13935\end{array}$ & Suelo & -- & Schuler et al. (2009) \\
\hline & Actinobacteria & Suelo & ex situ & Kallimanis et al. (2009) \\
\hline & $\begin{array}{l}\text { Rhodococcus } \\
\text { wratislaviensis IFP } 2016 \text { y } \\
\text { Rhodococcus } \\
\text { aetherivorans IFP } 2017\end{array}$ & Suelo & $\begin{array}{l}\text { ex situ } \\
100 \% \pm 7.3 \%\end{array}$ & Auffret et al. (2009) \\
\hline \multirow[t]{4}{*}{ Antraceno } & Actinobacteria & Suelo & $\begin{array}{l}\text { ex situ } \\
93.3 \%\end{array}$ & (Viñas Canals, 2005) \\
\hline & $\begin{array}{l}\text { Sphingobium } \\
\text { yanoikuyae B1 }\end{array}$ & & $\begin{array}{l}\text { ex situ } \\
28.7 \%\end{array}$ & Schuler et al. (2009) \\
\hline & $\begin{array}{l}\text { Sphingomonas } \\
\text { Paucimobilis EPA } 505\end{array}$ & $\begin{array}{l}\text { Reactivos } \\
\text { Químicos }\end{array}$ & in situ & $\begin{array}{l}\text { Desai et al. (2008); Story } \\
\text { et al. (2004) }\end{array}$ \\
\hline & $\begin{array}{l}\text { Mycobacterium } \\
\text { Gilvum VF1 }\end{array}$ & $\mathrm{nr}$ & $\begin{array}{l}\text { ex situ } \\
53 \%, 58 \%, 71 \%\end{array}$ & $\begin{array}{l}\text { Badejo et al. (2014); } \\
\text { Mutnuri et al. (2005) }\end{array}$ \\
\hline Pireno & Mycobacterium Gilvum VF1 & $\mathrm{nr}$ & $\begin{array}{l}\text { ex situ } \\
53 \%, 58 \%, 71 \%\end{array}$ & $\begin{array}{l}\text { Badejo et al. (2014); } \\
\text { Mutnuri et al. (2005) }\end{array}$ \\
\hline \multirow[t]{2}{*}{ Fluoranteno } & $\begin{array}{l}\text { Sphingomonas Paucimobilis EPA } \\
505\end{array}$ & $\mathrm{nr}$ & $\begin{array}{l}\text { ex situ } \\
85.9 \%-95 \%\end{array}$ & $\begin{array}{l}\text { (Desai et al., 2008; } \\
\text { Luning Prak \& } \\
\text { Pritchard, 2002) }\end{array}$ \\
\hline & $\begin{array}{l}\text { Sphingomonas paucimobilis NBRC } \\
13935\end{array}$ & Suelo & $\begin{array}{l}\text { in situ } \\
82 \%\end{array}$ & (Zhao, 2017) \\
\hline Metilfenantreno & Altererythrobactersp. & Agua de mar & $\begin{array}{l}\text { ex situ } \\
97.5 \%\end{array}$ & (Teramoto et al., 2010) \\
\hline \multirow[t]{3}{*}{ Alcanos } & $\begin{array}{l}\text { Ochrobactrum intermedium LMG } \\
3301\end{array}$ & Suelo & $\begin{array}{l}\text { in situ } \\
87 \%-89 \%\end{array}$ & Chai et al. (2015) \\
\hline & $\begin{array}{l}\text { Yersinia frederiksenii ATCC } 33641 \\
\text { Actinobacteria }\end{array}$ & $\mathrm{nr}$ & ex situ & (Das et al., 2011) \\
\hline & Alcanivorax hongdengensis A-11-3 & Suelo y agua & ex situ & (Pereda Largo, 2010) \\
\hline $\begin{array}{l}\text { Hidrocarburos } \\
\text { alifáticos } \\
\text { clorinados, } \\
\text { tricloroetileno }\end{array}$ & $\begin{array}{l}\text { Burkholderia cepacia ATCC } 25416 \\
\text { Burkholderia unamae, } \\
\text { Burkholderia kururiensis y } \\
\text { Burkholderia xenovorans }\end{array}$ & Suelos & $\begin{array}{l}\text { ex situ } \\
94.5 \% \\
50 \% \text { y } 45 \%\end{array}$ & $\begin{array}{l}\text { (Vandera \& Koukkou, } \\
\text { 2017) }\end{array}$ \\
\hline
\end{tabular}

\begin{tabular}{|c|c|c|}
\hline 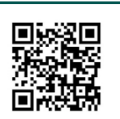 & (c) (i) () () & 191 \\
\hline
\end{tabular}




\section{Revista de

Revista de Ciencias Ambientales (Trop J Environ Sci) e-ISSN: 2215-3896 (Enero-Junio, 2022) . Vol 56(1): 178-208 DOI: https://doi.org/10.15359/rca.56-1.9 Open Access: www.revistas.una.ac.cr/ambientales e-mail: revista.ambientales@una.ac.cr Rodríguez-Gonzales A., Zárate-Villarroel S., Bastida-Codina A.

\begin{tabular}{|c|c|c|c|c|}
\hline Contaminantes & Bacteria biorremediadora & $\begin{array}{l}\text { Medios de vida } \\
\text { y/o material } \\
\text { contaminado }\end{array}$ & $\begin{array}{l}\text { Porcentaje de } \\
\text { biorremediación } \\
\text { y tipo de } \\
\text { tratamiento }\end{array}$ & Referencias \\
\hline Benzo (a) pireno & Rhizobium tropici & Suelos & $\begin{array}{l}\text { in situ } \\
45 \%-50 \%\end{array}$ & $\begin{array}{l}\text { Wong-Villarreal et al. } \\
\text { (2017) }\end{array}$ \\
\hline \multirow[t]{2}{*}{ Diesel } & Acinetobacter calcoaceticus CA16 & $\mathrm{nr}$ & ex situ & (Ho et al., 2017) \\
\hline & Actinobacteria & $\mathrm{nr}$ & $\begin{array}{l}\text { in situ } \\
34.4 \% \text { y } 88 \% \text {, } \\
77 \%-100 \%\end{array}$ & \\
\hline $\begin{array}{l}\text { Antraceno y } \\
\text { pireno }\end{array}$ & $\begin{array}{l}\text { Rhodococcus wratislaviensis IFP } \\
2016 \text { y } \\
\text { Rhodococcus aetherivorans IFP } 2017\end{array}$ & Suelo & $\begin{array}{l}\text { ex situ } \\
>90 \%\end{array}$ & Auffret et al. (2009) \\
\hline $\begin{array}{l}\text { Alcanos C22 } \\
\text { Alcanos C13-C44 }\end{array}$ & Acinetobacter baumannii M1 & $\mathrm{nr}$ & $\begin{array}{l}\text { in situ } \\
90 \%\end{array}$ & Tyagi et al. (2011) \\
\hline $\begin{array}{l}\text { Compuestos } \\
\text { aromáticos }\end{array}$ & Acinetobacter sp. ADP1 & $\mathrm{nr}$ & $\begin{array}{l}\text { in situ } \\
70 \% \\
\text { Degradación } \\
\text { del aceite usado } \\
\text { de automóviles } \\
\text { n-parafinas: } \\
\text { Decano } 0 \% \text {, } \\
\text { undecano } 0 \% \text {, } \\
\text { dodecano } 36.7 \% \text {, } \\
\text { hexadecano } 93.8 \% \text {, } \\
\text { Eicosano } 87 \% \\
\text { pentacosano } 85.3 \% \\
80 \% \text { triacontano }\end{array}$ & (Romero Lacal, 2008) \\
\hline \multirow[t]{2}{*}{$\begin{array}{l}\text { (Hidrocarburos } \\
\text { alifáticos } \\
\text { Mezclas de } \\
\text { n-alcanos }\end{array}$} & Alcanivorax borkumensis & $\mathrm{nr}$ & $\begin{array}{l}\text { Sin dato } \\
\text { ex situ } \\
\text { in situ } \\
80 \%-90 \%\end{array}$ & (van Beilen et al., 2004) \\
\hline & Nocardioides sp. Strain CF8 & $\mathrm{nr}$ & $\begin{array}{l}\text { in situ } \\
30 \% \text { butano } \\
84 \%-95 \% \\
96 \%-99 \%\end{array}$ & $\begin{array}{l}\text { (Vandera \& Koukkou, } \\
\text { 2017) }\end{array}$ \\
\hline Alcanos C5-C36 & $\begin{array}{l}\text { Alcanivorax } \\
\text { diéselolei } \mathrm{B} 5\end{array}$ & agua & $\begin{array}{l}\text { in situ } \\
90 \% \\
60 \%-70 \%\end{array}$ & (Kaplan \& Kitts, 2004) \\
\hline Alcanos C18-C24 & Alcanivorax dieselolei B5 & Agua & Ex situ & (Lai, 2012) \\
\hline
\end{tabular}

\begin{tabular}{|c|c|c|c|c|}
\hline 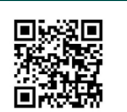 & (c) () & $\underbrace{\infty}_{\text {AMBinNALES }}$ & $\frac{10 \%}{20}$ & 192 \\
\hline
\end{tabular}




\section{Revista de Descle
Since 1980 CIENCIAS AMBIENTALES Tropical Journal of Environmental Sciences}

Revista de Ciencias Ambientales (Trop J Environ Sci) e-ISSN: 2215-3896 (Enero-Junio, 2022) . Vol 56(1): 178-208 DOI: https://doi.org/10.15359/rca.56-1.9 Open Access: www.revistas.una.ac.cr/ambientales e-mail: revista.ambientales@una.ac.cr Rodríguez-Gonzales A., Zárate-Villarroel S., Bastida-Codina A.

\begin{tabular}{|c|c|c|c|c|}
\hline Contaminantes & Bacteria biorremediadora & $\begin{array}{l}\text { Medios de vida } \\
\text { y/o material } \\
\text { contaminado }\end{array}$ & $\begin{array}{l}\text { Porcentaje de } \\
\text { biorremediación } \\
\text { y tipo de } \\
\text { tratamiento }\end{array}$ & Referencias \\
\hline \multirow[t]{5}{*}{ n-alcanos } & Actinobacteria & Suelo & $\begin{array}{l}\text { in situ } \\
90 \% \\
\text { in situ } \\
90 \%\end{array}$ & (Romero Lacal, 2008) \\
\hline & Pseudomonas Aeruginosa MGP-1 & $\mathrm{nr}$ & $\begin{array}{l}\text { ex situ } \\
\text { C16: } 96 \%-92.4 \% \\
\text { C24: } 94.8 \%-91.3 \% \\
\text { C30: } 93.6 \%-89.4 \% \\
\text { C40: } 93.5 \%-88.3 \%\end{array}$ & (Salgado et al., 2007) \\
\hline & Rhodococcus opacus R7 & & $\begin{array}{l}\text { in situ } \\
\text { Carbons: } \\
\text { C12: } 88 \% \\
\text { C16: } 69 \% \\
\text { C20: } 51 \% \\
\text { C24: } 78 \% \\
84 \%-95 \% \\
96 \%-99 \%\end{array}$ & $\begin{array}{l}\text { Pathak et al. (2016); } \\
\text { (Zampolli et al., 2014) }\end{array}$ \\
\hline & Dietzia & $\mathrm{nr}$ & ex situ & (Bihari, 2011) \\
\hline & Pseudomonas butanavora & $\mathrm{nr}$ & ex situ & (Kurth et al., 2008) \\
\hline \multirow[t]{3}{*}{ o-xyleno } & Actinobacteria & & $\begin{array}{l}\text { ex situ } \\
\text { 56.0-89.8 \% } \\
\text { C12: } 88 \% \\
\text { C16: } 69 \% \\
\text { C20: } 51 \% \\
\text { C24: } 78 \% .\end{array}$ & (Zampolli et al., 2014) \\
\hline & $\begin{array}{l}\text { Rhodococcus } \\
\text { wratislaviensis IFP } 2016 \text { y } \\
\text { Rhodococcus } \\
\text { aetherivorans IFP } 2017\end{array}$ & Suelo & $\begin{array}{l}\text { ex situ } \\
100 \% \pm 2.4 \%\end{array}$ & Auffret et al. (2009) \\
\hline & $\begin{array}{l}\text { Rhodococcus } \\
\text { wratislaviensis }\end{array}$ & $\mathrm{nr}$ & $\begin{array}{l}\text { in situ } \\
100 \% \\
63,2 \% \pm 1,98 \%\end{array}$ & Zhao et al. (2017) \\
\hline $\begin{array}{l}\text { Policlorobifenilos } \\
\text { (PCBs) }\end{array}$ & $\begin{array}{l}\text { Rhodococcus } \\
\text { opacus R7 }\end{array}$ & $\mathrm{nr}$ & $\begin{array}{l}\text { in situ } \\
36 \%\end{array}$ & (Xu et al., 2016) \\
\hline Policlorobifenilo & Rhodococcus jostii RHA1 & $\mathrm{nr}$ & in situ & Takeda et al. (2010) \\
\hline
\end{tabular}




\section{Revista de CIENCIAS AMBIENTALES Tropical Journal of Environmental Sciences}

Revista de Ciencias Ambientales (Trop J Environ Sci) e-ISSN: 2215-3896

(Enero-Junio, 2022) . Vol 56(1): 178-208 DOI: https://doi.org/10.15359/rca.56-1.9 Open Access: www.revistas.una.ac.cr/ambientales e-mail: revista.ambientales@una.ac.cr

Rodríguez-Gonzales A., Zárate-Villarroel S., Bastida-Codina A.

\begin{tabular}{|c|c|c|c|c|}
\hline Contaminantes & Bacteria biorremediadora & $\begin{array}{l}\text { Medios de vida } \\
\text { y/o material } \\
\text { contaminado }\end{array}$ & $\begin{array}{l}\text { Porcentaje de } \\
\text { biorremediación } \\
\text { y tipo de } \\
\text { tratamiento }\end{array}$ & Referencias \\
\hline \multirow{5}{*}{$\begin{array}{l}\text { Cresol, } \\
\text { benzoato, } \\
\text { Fenol, } \\
\text { Tolueno }\end{array}$} & $\begin{array}{l}\text { Sphingomonas } \\
\text { Paucimobilis EPA } 505\end{array}$ & Suelo & $\begin{array}{l}\text { ex situ } \\
85.9 \%\end{array}$ & (Desai et al., 2008) \\
\hline & $\begin{array}{l}\text { Pseudomona putida F1 } \\
\text { Pseudomona putida DOT-T1E } \\
\text { Ralstonia picketii } \\
\text { Burkholderia cepacia }\end{array}$ & $\mathrm{nr}$ & exsitu & $\begin{array}{l}\text { (Romero Lacal, 2008; } \\
\text { Smith et al., 2013) }\end{array}$ \\
\hline & Pseudomonas Aeruginosa MGP-1 & $\mathrm{nr}$ & $\begin{array}{l}\text { ex situ } \\
<85 \%\end{array}$ & (Salgado et al., 2007) \\
\hline & $\begin{array}{l}\text { Rhodococcus wratislaviensis IFP } \\
2016 \text { y } \\
\text { Rhodococcus aetherivorans IFP } 2017\end{array}$ & $\mathrm{nr}$ & $\begin{array}{l}\text { ex situ } \\
100 \% \pm 2 \%\end{array}$ & Auffret et al. (2009) \\
\hline & Planctomyces sp. SH-PL14 & $\begin{array}{l}\text { Desecho de } \\
\text { agua }\end{array}$ & ex situ & Silva et al. (2012) \\
\hline xileno & $\begin{array}{l}\text { Rhodococcus wratislaviensis IFP } \\
2016 \text { y } \\
\text { Rhodococcus aetherivorans IFP } 2017\end{array}$ & Suelo & $\begin{array}{l}\text { ex situ } \\
100 \% \pm 2.4 \%\end{array}$ & Auffret et al. (2009) \\
\hline $\begin{array}{l}\text { Diferentes } \\
\text { Hidrocarburos } \\
\text { aromáticos } \\
\text { policiclicos } \\
\text { PAHs }\end{array}$ & $\begin{array}{l}\text { Novosphingobiumaromaticivorans } \\
\text { DSM } 12444\end{array}$ & $\mathrm{nr}$ & $\begin{array}{l}\text { ex situ } \\
93.2 \%\end{array}$ & $\begin{array}{l}\text { Keum et al. (2008); } \\
\text { Lyytikäinen, 2007; Zhou } \\
\text { et al. (2011) }\end{array}$ \\
\hline
\end{tabular}

\section{Factores fisicoquímicos que aceleran el proceso de biorremediación de hidrocarburos}

La biodegradación aerobia de compuestos de hidrocarburos presentes en suelos y cuerpos de agua dependen de varios factores (Figura 3). Uno es la estructura de los microorganismos nativos, ya que esto viene influenciado por la concentración del contaminante si es reciente o antigua, así como la salinidad del ecosistema, el oxígeno, el pH y la disponibilidad de nutrientes. La eficiencia de tratamiento de sitios contaminados por hidrocarburos, mediante la técnica de biorremediación, depende de la velocidad de degradación de los contaminantes (Hidalgo et al., 2020; Vandera \& Koukkou, 2017). Los HAPs sufren transformaciones fisicoquímicas al ingresar al ambiente, estas son volatilización, fotolisis, adsorción y oxidación debido a la presencia de oxígeno abundante. La biodegradación microbiana de estos compuestos es un proceso ambiental determinante para su destino final en los ecosistemas (Hidalgo et al., 2020). El suelo es un componente ambiental que genera vida gracias a su composición, contiene elementos biológicos, químicos minerales y físicos. Los componentes químicos facilitan la erosión de las rocas, la materia orgánica llamada humus, y la biomasa compacta, la cual está formada por seres vivos, gases y agua.

留




\section{Revista de CIENCIAS AMBIENTALES Tropical Journal of Environmental Sciences}

Revista de Ciencias Ambientales (Trop J Environ Sci) e-ISSN: 2215-3896 (Enero-Junio, 2022) . Vol 56(1): 178-208 DOI: https://doi.org/10.15359/rca.56-1.9 Open Access: www.revistas.una.ac.cr/ambientales e-mail: revista.ambientales@una.ac.cr

Rodríguez-Gonzales A., Zárate-Villarroel S., Bastida-Codina A.

En un proceso de biorremediación, es importante la heterogeneidad física del suelo. Al existir suelos franco arenosos, arcillosos y con un alto contenido de materia orgánica, que al parecer tienen influencia en el tratamiento, afectando a la biodegradación de los hidrocarburos, se ha podido observar que existe un gran número de unidades formadoras de colonias de tipo autóctonas con capacidad de mineralizar compuestos orgánicos, mediante el uso del carbono e hidrógeno de los compuestos de petróleo como sustrato (Vandera \& Koukkou, 2017). Los HAPs están presentes tanto en ambientes terrestres como marinos, por ello, las comunidades microbianas en entornos de hidrocarburos se ven influenciadas por la complejidad, la concentración y el tiempo de exposición a las mezclas de estos componentes.

Los alcanos formados por mezclas de alcanos de tipo $\mathrm{C}_{10}-\mathrm{C}_{20}$ son más tóxicos que los de mayor número de átomos de $\mathrm{C}\left(\mathrm{C}_{20}-\mathrm{C}_{40}\right)$. También, se han investigado diferentes mezclas de petróleo (diésel, querosén) presentes en tres tipos de suelos diferentes y se observaron cambios en el RNA de las comunidades bacterianas, indicativo de que el tipo de mezcla de petróleo influyó en la degradación de hidrocarburos y en el tipo de población bacteriana presente (Figura 3) (López, 2021; Vandera \& Koukkou, 2017).

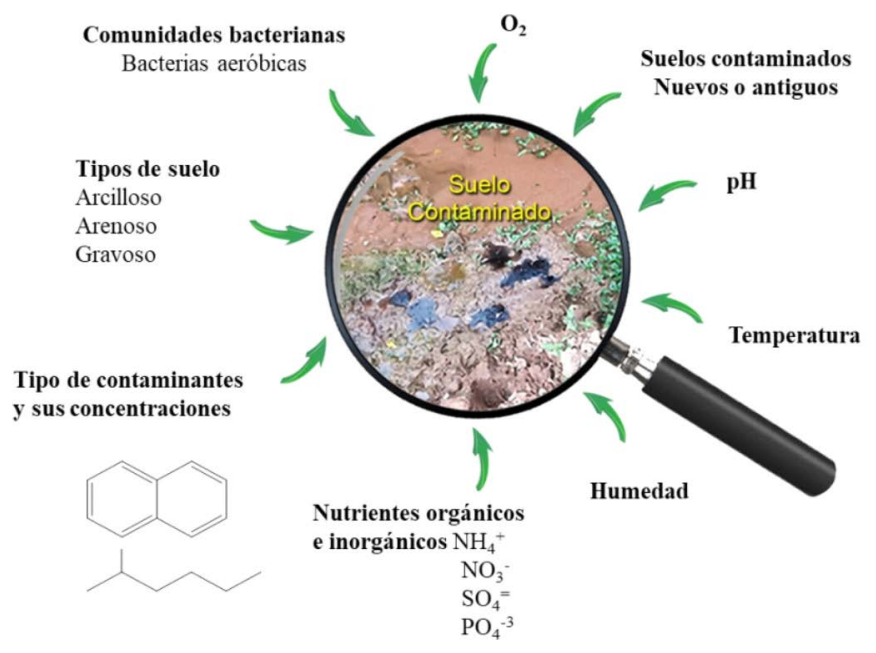

Figura 3. Suelo contaminado con HAPs y factores que intervienen en el proceso de biodegradación Vandera \& Koukkou, 2017).

Figure 3. Soil contaminated with PAHs and factors that intervene in the biodegradation process Vandera \& Koukkou, 2017).

\subsection{Sitios recientes y antiguos contaminados con hidrocarburos}

Algunos autores han observado que hay una reducción en la riqueza y diversidad de bacterias en sitios contaminados recientemente por hidrocarburos de petróleo, mientras que otros estudios demuestran un aumento en las unidades formadoras de colonias de bacterias, así como en su tasa de biodegradación en los sitios contaminados antiguos. Pero ambos estudios confirman

\begin{tabular}{|c|c|c|}
\hline 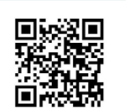 & (c) (1) (5) & 195 \\
\hline
\end{tabular}




\section{Revista de CIENCIAS AMBIENTALES Tropical Journal of Environmental Sciences}

Revista de Ciencias Ambientales (Trop J Environ Sci) e-ISSN: 2215-3896

(Enero-Junio, 2022) . Vol 56(1): 178-208

DOI: https://doi.org/10.15359/rca.56-1.9

Open Access: www.revistas.una.ac.cr/ambientales e-mail: revista.ambientales@una.ac.cr

Rodríguez-Gonzales A., Zárate-Villarroel S., Bastida-Codina A.

que los primeros en biodegradarse son los hidrocarburos alifáticos en comparación con los hidrocarburos aromáticos, ya que estos últimos contaminantes son muy estables debido a la presencia de los dobles enlaces (López et al., 2021).

Los microorganismos del suelo se ven afectados en gran medida por la contaminación a largo plazo. Por otro lado, la biodegradación se ve afectada por la contaminación, la competencia por los nutrientes $(\mathrm{N}, \mathrm{P}, \mathrm{C})$, la biodisponibilidad de los contaminantes, el tipo de suelo y la resistencia de las comunidades de microorganismos a la presencia de mezclas de hidrocarburos (Liang et al., 2016). La reducción de la diversidad microbiana podría deberse a amenazas ecológicas selectivas (Morais et al., 2016; Patel et al., 2016) por la presencia de TPH que genera hidrocarburos tóxicos para gran variedad de microorganismos, lo que hace que su biodegradación sea muy difícil (Hariyo, 2020; Liao et al., 2015).

\subsection{Influencia del pH en la biodegradación}

La recuperación de suelos contaminados con hidrocarburos depende de varios factores fisicoquímicos como el pH. Es sabido que las comunidades microbianas para realizar el proceso de biorremediación deben desarrollarse dentro de ciertos rangos de $\mathrm{pH}$, ya que determina el grado de absorción de iones por las partículas del suelo, afectando su solubilidad, movilidad y disponibilidad, siendo estos factores determinantes para el proceso de biorremediación (Hidalgo, 2020). Así, frente a pHs extremos $(>80<4)$, la biodegradación es muy lenta y los estudios muestran que los suelos contaminados por hidrocarburos son principalmente ácidos, por cuanto se limita el crecimiento de ciertos microorganismos en ciertos rangos. Una buena biodegradación debería presentar un $\mathrm{pH}$ entre 6 - 8, si se pretende que se mantengan largos períodos de biodegradación (7.4 - 7.8, pH óptimo). Un aspecto muy importante por considerar es que la variación de $\mathrm{pH}$ afecta tanto a la actividad del microorganismo como a la posible solubilización y absorción de los iones $\left(\mathrm{NH}_{4}+, \mathrm{Mg}^{2+}, \mathrm{Ca}^{2+}, \mathrm{NO}_{3}^{-}, \mathrm{PO}_{4}^{3-}, \mathrm{Cl}^{-}\right)$presentes en los contaminantes (Hariyo, 2020).

\subsection{Adición de nutrientes y oxígeno}

La contaminación por petróleo provoca un desequilibrio en las relaciones carbono-nitrógeno en el sitio contaminado, por lo que es importante realizar la adición de nutrientes como aceptores de electrones como es el caso de los átomos de $\mathrm{P}, \mathrm{N}, \mathrm{O}$, con el objetivo de promover el crecimiento de microorganismos nativos que realizarán la biorremediación. Las tasas de oxígeno en el suelo contaminado disminuyen, debido a las altas concentraciones de hidrocarburos. Este elemento es un aceptor de electrones en los procesos de biorremediación aeróbica, por lo tanto, mejora el crecimiento de bacterias (Vandera \& Koukkou, 2017). Estudios realizados mostraron que la entrada de oxígeno a los sitios anóxicos puede tener un efecto importante en el aumento de la diversidad bacteriana que resulta en la cantidad de HAP, así los genes degradadores serían gamma-proteobacterias no determinadas y Acidovorax (Singleton et al., 2018). Por otro lado, el aumento de bacterias puede ser causado por degradadores potenciales y disminución

\begin{tabular}{|c|c|c|c|c|c|}
\hline 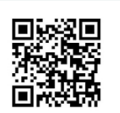 & (c) (1) (9) & $\underbrace{}_{\text {AMBENTIIES }}$ & $\frac{O \%}{2)}$ & 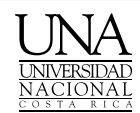 & 196 \\
\hline
\end{tabular}




\section{Revista de CIENCIAS AMBIENTALES Tropical Journal of Environmental Sciences}

Revista de Ciencias Ambientales (Trop J Environ Sci)

e-ISSN: 2215-3896

(Enero-Junio, 2022) . Vol 56(1): 178-208

DOI: https://doi.org/10.15359/rca.56-1.9

Open Access: www.revistas.una.ac.cr/ambientales

e-mail: revista.ambientales@una.ac.cr

Rodríguez-Gonzales A., Zárate-Villarroel S., Bastida-Codina A.

gases, porque los poros de los suelos se llenan de agua y no de oxígeno, factor esencial para que tenga lugar la biorremediación en condiciones aerobias (Hariyo, 2020).

\section{Discusión}

El estudio de la composición de las comunidades microbianas presentes en suelos contaminados es esencial para llevar a cabo la biorremediación. Los microorganismos sobreviven en todos los lugares de la biosfera, debido a que su actividad metabólica es asombrosa. Las bacterias son capaces de crecer en condiciones ambientales extremas de $\mathrm{pH}$, temperatura, humedad, oxígeno, nutrientes y composición de suelo, estos son factores externos de la biorremediación que ayudan a conseguir las condiciones favorables. La capacidad nutricional de los microorganismos es completamente variada, por lo que se les utiliza como biorremediadores de contaminantes ambientales como es el petróleo y sus derivados. Esta técnica tiene un gran potencial para la recuperación de sitios contaminados y está muy involucrada en la degradación y erradicación de hidrocarburos procedentes del petróleo, llevándose a cabo de manera enzimática y con la intervención de sus genes, a través del metabolismo catabólico de las enzimas presentes en dichos microorganismos, por lo que tiene un papel de contribución positiva para resolver muchos problemas ambientales, al ser una biotecnología económica y amigable con el medio ambiente, porque no produce impactos ambientales negativos resultado de los procesos de tratamiento de los ecosistemas contaminados. De forma similar, las condiciones bióticas y abióticas determinan la tasa de degradación del contaminante. Los consorcios bacterianos más utilizados para el tratamiento de hidrocarburos policíclicos son la Sphingomonas paucimobilis EPA 505, Burkholderia sp. y Stenotrophomonas, entre otras más.

Las técnicas de biorremediación más aplicadas actualmente en el mundo son la bioestimulación, bioaumento, bioventilación, biopilas y bioatenuación. Todas tienen sus propias ventajas y desventajas porque tienen su propia aplicación específica.

\section{Conclusiones}

Se puede concluir que los países a nivel global y, en particular, los latinoamericanos dependen de la generación de recursos económicos provenientes de los recursos naturales no renovables como el petróleo y sus derivados. Esta dependencia produce graves problemas ambientales y varias consecuencias negativas como la degradación de los ecosistemas de donde se extraen estos productos. Los afectados directos son las comunidades indígenas y campesinas de los países latinoamreicanos, porque de sus territorios se extraen los recursos, ellos sufren cada día la pérdida de sus fuentes de vida, como el agua, la flora y fauna.

La composición química de los compuestos de petróleo es compleja, pues dependiendo de sus características químicas y pueden clasificarse como fácilmente biodegradables, medianamente biodegradables y no biodegradables o llamados recalcitrantes.

\begin{tabular}{|c|c|c|c|c|c|}
\hline 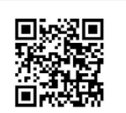 & (c) (1) (5) () & $\theta_{\text {AMEIENTIISS }}$ & $\frac{10 \%}{20}$ & $\frac{\text { UNA }}{\frac{\text { UNIVERSIDAD }}{\text { NACIONAL }}}$ & 198 \\
\hline
\end{tabular}




\section{Revista de CIENCIAS AMBIENTALES Tropical Journal of Environmental Sciences}

Revista de Ciencias Ambientales (Trop J Environ Sci)

e-ISSN: 2215-3896

(Enero-Junio, 2022) . Vol 56(1): 178-208

DOI: https://doi.org/10.15359/rca.56-1.9

Open Access: www.revistas.una.ac.cr/ambientales e-mail: revista.ambientales@una.ac.cr

Rodríguez-Gonzales A., Zárate-Villarroel S., Bastida-Codina A.

Se ha presentado un resumen de los riesgos para la salud de los hidrocarburos aromáticos, cuando las personas se exponen a estos compuestos; se analizaron las principales características de los alcanos, hidrocarburos monoaromáticos y los poliaromáticos. Como ejemplo, se presenta la ruta metabólica de degradación bacteriana del fenantreno, así como los principios generales de degradación microbiana aeróbica de hidrocarburos aromáticos y alifáticos. También se analizaron minuciosamente los microorganismos con capacidad de biorremediar sitios contaminados por hidrocarburos, así como los genes involucrados y sus enzimas de las bacterias.

En este artículo de revisión se centró la atención particularmente en los hidrocarburos aromáticos policíclicos; estos compuestos pueden ser biodegradados por un consorcio o comunidades bacterianas individuales, como es el caso del fenantreno (compuesto aromático) que puede ser biodegradado por 11 diferentes cepas bacterias (Sphingobium, Sphingomonas, Acidovorax, Alkaligenes, Actinobacterias, Burkholderia sp., Rhizobium sp., Pseudomonas sp., Stenotrophomonas, Sinorhizobium y Esfingomonas). Las bacterias que biodegradaban el acenafteno y al naftaleno pertenecen principalmente al grupo Sphingomonas y Rhodococcus. El antraceno fue biodegradado por diferentes bacterias tales como Actinobacteria, Sphingobium, Shingomonas y Mycobacterium y las dos últimas bacterias biodegradan, además, al pireno y el fluoranteno. Los alcanos fueron biodegradados por diferentes grupos de bacterias, Ochrobactrum intermedium, Yersinia frederiksenii, Alkanivorax, Methylosinus; los hidrocarburos alifáticos clorados y el tricloroetileno fueron biodegradados por un consorcio de diferentes bacterias; y el diésel fue biodegradado por Rhizobium tropici y Actinobacterias. Una mezcla de antraceno, pireno, o-xileno, PCB, cresol, benzoato, fenol y tolueno fueron degradados por un consorcio de bacterias distintas del grupo Rhodococcus. Se evidenció en la bibliografía que existen más de 136 bacterias biodegradadoras de hidrocarburos y sus derivados, en procesos aeróbicos como anaeróbicos, mediante métodos in situ o ex situ, principalmente en suelos y muy pocos en agua. Por otro lado, en algunas publicaciones no informaron cuáles fueron los genes que codifican a las enzimas o proteínas involucradas en la biorremediación, para comprender sus mecanismos de acción.

Se puede verificar en detalle en el (Cuadro 2) los nombres de los contaminantes, el tipo de bacteria que tiene la capacidad de biodegradar hidrocarburos con diferentes características químicas, los medios en los que se encontraron o hicieron las investigaciones para determinar el poder de biodegradación, los porcentajes de biorremediación obtenidos, genes que intervinieron y las referencias bibliográficas.

Se realizó la revisión de artículos científicos sobre los factores fisicoquímicos que aceleran el proceso de biorremediación, variables determinantes a tomar en cuenta en trabajos de investigación sobre biorremediación. En los sitios contaminados recientemente, se ve reducida la riqueza de la diversidad bacteriana, mientras que en sitios contaminados hace mucho tiempo se informa que la cantidad de bacterias y su tasa de biodegradación se incrementó. El pH de los sitios contaminados es determinante para que los microorganismos desarrollen el proceso de biorremediación, dependiente de esta variable para la absorción de iones por las partículas del

\begin{tabular}{|c|c|c|c|c|}
\hline 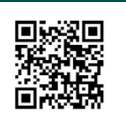 & (c) (i) (5) () & 8 & $\frac{O \%}{\text { euna }}$ & 199 \\
\hline
\end{tabular}




\section{Revista de CIENCIAS AMBIENTALES Tropical Journal of Environmental Sciences}

Revista de Ciencias Ambientales (Trop J Environ Sci)

e-ISSN: 2215-3896

(Enero-Junio, 2022) . Vol 56(1): 178-208

DOI: https://doi.org/10.15359/rca.56-1.9

Open Access: www.revistas.una.ac.cr/ambientales e-mail: revista.ambientales@una.ac.cr

Rodríguez-Gonzales A., Zárate-Villarroel S., Bastida-Codina A.

suelo, y, por tanto, la solubilidad, movilidad y disponibilidad que mejoran en rangos de $\mathrm{pH}$ de 7.4 a 7.8, por tanto, la biodegradación del hidrocarburo es óptima.

Otras variables fisicoquímicas son la adición de nutrientes y oxígeno, porque el artículo de revisión presente se centró en procesos de biorremediación aerobia. Es preciso agregar a los sitios contaminados nutrientes como aceptores de electrones como el fósforo, nitrógeno y oxígeno, este último en particular para favorecer el crecimiento bacteriano, de preferencia de los microorganismos nativos aerobios del suelo $\mathrm{y}$, a la vez, es un excelente aceptor de electrones en tratamientos aerobios.

Es importante considerar la influencia de la temperatura en estos tratamientos, dado que favorece el crecimiento de la diversidad bacteriana en el suelo contaminado y, así mismo, afecta la tasa de volatilidad de los compuestos con estas características, así como también afecta en el metabolismo microbiano, logrando una mejor degradación de los hidrocarburos. La humedad es otro factor clave porque influye en el crecimiento bacteriano y su metabolismo, sirve como medio de transporte de nutrientes y oxígeno, los porcentajes óptimos de saturación del agua en el suelo contaminado es del $30 \%$ al $90 \%$.

Se buscó aportar con esta revisión bibliográfica, opciones de solución viables ambiental, económica y socialmente a variados problemas de contaminación por hidrocarburos de los ecosistemas latinoamericanos, que tienen que enfrentar los diferentes Gobiernos.

\section{9. Ética y conflicto de intereses}

Las personas autoras declaran que han cumplido totalmente con todos los requisitos éticos y legales pertinentes, tanto durante el estudio como en la producción del manuscrito; que no hay conflictos de intereses de ningún tipo; que todas las fuentes financieras se mencionan completa y claramente en la sección de agradecimientos, y que están totalmente de acuerdo con la versión final editada del artículo.

\section{Agradecimientos}

A la Revista y las personas revisoras por sus atinados comentarios y sugerencias a la versión final del artículo.

\begin{tabular}{|c|c|c|c|c|c|}
\hline 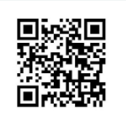 & (c) (1) (9) (O) & $\overbrace{\text { AMBiENTALES }}^{\infty}$ & $\frac{\mid 0 \%}{20}$ & $\frac{\text { UNA }}{\frac{\text { UNIVERSIDAD }}{\text { UNACIONAL }}}$ & 200 \\
\hline
\end{tabular}




\section{Revista de CIENCIAS AMBIENTALES Tropical Journal of Environmental Sciences}

Revista de Ciencias Ambientales (Trop J Environ Sci) e-ISSN: 2215-3896 (Enero-Junio, 2022) . Vol 56(1): 178-208 DOI: https://doi.org/10.15359/rca.56-1.9 Open Access: www.revistas.una.ac.cr/ambientales e-mail: revista.ambientales@una.ac.cr

Rodríguez-Gonzales A., Zárate-Villarroel S., Bastida-Codina A.

\section{Referencias}

Abasolo Pacheco, F., \& Morante Carriel, L. A. (2020). Bacterias degradadoras de hidrocarburos a partir de suelos contaminados con hidrocarburos. Biblioteca Colloquium. http://colloquiumbiblioteca.com/index.php/web/article/view/33

Araujo J., Yegres, F., Barreto, G., Antequera, A., Depool, B. \& Rojas, Y. (2016). Biocatalizadores fúngicos hidrocarbonoclásticos del género Aspergillus para la descontaminación de agua con hidrocarburos policíclicos aromáticos (HPAs). Revista Cubana de Quimica, 28(2), 703-735. https://www.redalyc.org/articulo.oa?id=443546334013

Arrieta Ramírez, O., Rivera, Rivera, A., Arias Marín, L., Rojano, B., Ruiz, O. \& Cardona Gallo, S. (2012). Biorremediación de un suelo con diésel mediante el uso de microorganismos autóctonos. Gestión y Ambiente, 15(1), 27-39. https://www.redalyc.org/articulo.oa?id=169424101004

Auffret, M., Labbe, D., Thouand, G., Greer, C. W., \& Fayolle-Guichard, F. (2009). Degradation of a mixture of hydrocarbons, gasoline, and diesel oil additives by Rhodococcus aetherivorans and Rhodococcus wratislaviensis. Appl Environ Microbiol, 75(24), 7774-7782. https://doi.org/10.1128/AEM.01117-09

Arulazhagan, P., Al-Shekri, K., Huda, Q., Godon, J. J., Basahi, J. M., \& Jeyakumar, D. (2016). Biodegradation of polycyclic aromatic hydrocarbons by an acidophilic Stenotrophomonas maltophilia strain AJH1 isolated from a mineral mining site in Saudi Arabia. Extremophiles, 21(1), 163-174. https://doi.org/10.1007/s00792-016-0892-0

Azubuike, Ch. Ch., Chikere Ch.B. \& Okpokwasili G. (2016). Bioremediation techniques-classification based on site of application: principles, advantages, limitations, and prospects. World J Microbiol Biotechnol 32:180. Bioremediation techniques-classification based on site of application: principles, advantages, limitations and prospects | SpringerLink

Badejo A. C., Chung W. H., Kim N. S., Chai J. C., Lee Y. S. \& Jung K. H.(2014). Energy metabolism in Mycobacterium gilvum PYR-GCK: insights from transcript expression analyses following two states of induction. PLoS One, 9(6), e99464. https://doi.org/10.1371/journal.pone.0099464

Bargiela, R., Mapelli, F., Rojo, D., Chouai, B., Tornés, J., Borin, S., Richeter, M., Del Pozo, M., Cappello, S., Gertler, C., Genovese, M., Denaro, R., Martínez, M., Fodelianakis, S., Amer, R., Bigazzi, D., Han, X., Chen, J., Chernikova, T... \& Ferrer, M. (2015). Bacterial population and biodegradation potential in chronically crude oil-contaminated marine sediments are strongly linked to temperature. Sci Rep, 5, 11651. https://doi.org/10.1038/srep11651

Bihari Z., S. A., Szabo Z., Blastyak A., Zombori Z., Balazs M. \& Kiss I. (2011). Functional analysis of long-chain n-alkane degradation by Dietzia spp. FEMS Microbiology Letters, 316(2), 100-107. https://doi.org/10.1111/j.1574-6968.2010.02198.x

\begin{tabular}{|c|c|c|c|c|c|}
\hline 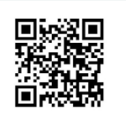 & (c) (1) (9) & $\underbrace{}_{\text {AMBENTIIES }}$ & $\frac{10 \%}{20}$ & $\frac{\text { UNA }}{\frac{\text { UNIVERSIDAD }}{\text { NACIONAL }}}$ & 201 \\
\hline
\end{tabular}




\section{Revista de CIENCIAS AMBIENTALES Tropical Journal of Environmental Sciences}

Revista de Ciencias Ambientales (Trop J Environ Sci) e-ISSN: 2215-3896 (Enero-Junio, 2022) . Vol 56(1): 178-208 DOI: https://doi.org/10.15359/rca.56-1.9 Open Access: www.revistas.una.ac.cr/ambientales e-mail: revista.ambientales@una.ac.cr

Rodríguez-Gonzales A., Zárate-Villarroel S., Bastida-Codina A.

Chai L. J., Jiang X. W., Zhang F., Zheng B.W., Shu F.C.\& Wang Z.L. (2015). Isolation and characterization of a crude oil degrading bacteria from formation water: comparative genomic analysis of environmental Ochrobactrum intermedium isolate versus clinical strains. $J$ Zhejiang Univ Sci B, 16(10), 865-874. https://doi.org/10.1631/jzus.B1500029

Coll Almela, M. D. (2021). Construyendo materia orgánica en suelos degradados bajo clima semiárido mediante el uso de enmiendas orgánicas [Tesis de doctorado, Universidad de Murcia]. Repositorio Institucional de la Universidad de Murcia. http://hdl.handle.net/10201/101951

Das, R., Shimamoto, T., \& Arifuzzaman, M. (2011). A Novel msDNA (Multicopy Single-Stranded DNA) Strain Present in Yersinia frederiksenii ATCC 33641 Contig01029 Enteropathogenic Bacteria with the Genomic Analysis of It's Retron. J Pathog, 2011, 1-6. https://doi.org/10.4061/2011/693769

Desai, A. M., Autenrieth, R. L., Dimitriou-Christidis, P., \& McDonald, T. J. (2008). Biodegradation kinetics of select polycyclic aromatic hydrocarbon (PAH) mixtures by Sphingomonas paucimobilis EPA505. Biodegradation, 19(2), 223-233. https://doi.org/10.1007/s10532-007-9129-3

Ding, G. C., Heuer, H., \& Smalla, K. (2012). Dynamics of bacterial communities in two unpolluted soils after spiking with phenanthrene: soil type specific and common responders. Front Microbiol, 3, 290. https://doi.org/10.3389/fmicb.2012.00290

Feng, L., Jiang, X., Huang Y., Wen, D., Fu, T., \& Fu, R. (2021). Petroleum hydrocarbon-contaminated soil bioremediation assisted by isolated bacterial consortium and sophorolipid. Environmental Pollution, 273, 1-8. https://doi.org/10.1016/j.envpol.2021.116476

Fritz Feichtner, M. (2020). Toxic Ghost Acres, o la dinámica de la eliminación de desechos de producción de petróleo en la Amazonía ecuatoriana, de los años setenta a noventa. Rachel Carson Center, 10(1), 23-51. https://doi.org/10.32991/2237-2717.2020v10i1.p23-51

Guevara Ramírez, G. V. (2017). La identidad cultural de los jóvenes Weenhayek con relación a los cambios que atraviesa su sociedad [Tesis de grado, Universidad de Mayor de San Andrés]. Repositorio Institucional de Universidad de Mayor de San Andrés. https://repositorio.umsa. bo/bitstream/handle/123456789/14921/234.pdf? sequence $=1 \&$ isAllowed $=y$

Ghosal, D., Ghosh, S., Dutta, T. K., \& Ahn, Y. (2016). Current State of Knowledge in Microbial Degradation of Polycyclic Aromatic Hydrocarbons (PAHs): A Review. Front Microbiol, 7(1), 1-27. https://doi.org/10.3389/fmicb.2016.01369

Hariyo, D. D. (2020). Comunidades microbianas asociadas a la remoción de fenantreno en suelo: efecto de la aplicación de Medicago sativa L. en el proceso de biorremediación [Tesis doctoral, Universidad Nacional de La Plata]. Repositorio Institucional de la UNLP. http://sedici.unlp. edu.ar/handle/10915/110010

\begin{tabular}{|c|c|c|c|c|c|}
\hline 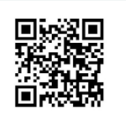 & (c) (1) (5) () & $\theta_{\text {AMEIENTIISS }}$ & $\frac{10 \%}{20}$ & $\frac{\text { UNA }}{\frac{\text { UNIVERSIDAD }}{\text { NACIONAL }}}$ & 202 \\
\hline
\end{tabular}




\section{Revista de CIENCIAS AMBIENTALES Tropical Journal of Environmental Sciences}

Revista de Ciencias Ambientales (Trop J Environ Sci) e-ISSN: 2215-3896 (Enero-Junio, 2022) . Vol 56(1): 178-208 DOI: https://doi.org/10.15359/rca.56-1.9 Open Access: www.revistas.una.ac.cr/ambientales e-mail: revista.ambientales@una.ac.cr

Rodríguez-Gonzales A., Zárate-Villarroel S., Bastida-Codina A.

Hernández-Valencia I., Manuel Lárez, L., \& Vicente García, J. (2017). Evaluación de la toxicidad de un suelo contaminado con diferentes tipos de crudos sobre la germinación de dos pastos tropicales. BIOAGRO, 29(2), 73-82. http://ve.scielo.org/scielo. php?script=sci_arttext\&pid=S1316-33612017000200001

Hidalgo, K. J., Sierra-Garcia, I. N., Dellagnezze, B. M., \& de Oliveira, V. M. (2020). Metagenomic Insights Into the Mechanisms for Biodegradation of Polycyclic Aromatic Hydrocarbons in the Oil Supply Chain. Front Microbiol, 11, 561506. https://doi.org/10.3389/fmicb.2020.561506

Heiss-Blanquet, S., Benoit, Y., Marechaux, C., \& Monot, F. (2005). Assessing the role of alkane hydroxylase genotypes in environmental samples by competitive PCR. J Appl Microbiol, 99(6), 1392-1403. https://doi.org/10.1111/j.1365-2672.2005.02715.x

Ho, M. T., Weselowski, B., \& Yuan, Z. Ch. (2017). Complete Genome Sequence of Acinetobacter calcoaceticus CA16, a Bacterium Capable of Degrading Diesel and Lignin. American Society for Microbiology. 5(24). https://doi.org/10.1128/genomeA.00494-17

Hu, B., Wang, M., Geng, S., Wen, L., Wu, M., Nie, Y., \& Wu, X. L. (2020). Metabolic Exchange with Non-Alkane-Consuming Pseudomonas stutzeri SLG510A3-8 Improves n-Alkane Biodegradation by the Alkane Degrader Dietzia sp. Strain DQ12-45-1b. Appl Environ Microbiol, 86(8), 1-2. https://doi.org/10.1128/AEM.02931-19

Kallimanis, A., Kavakiotis, K., Perisynakis, A., Sproer, C., Pukall, R., Drainas, C., \& Koukkou, A. I. (2009). Arthrobacter phenanthrenivorans sp. nov., to accommodate the phenanthrene-degrading bacterium Arthrobacter sp. strain Sphe3. Int J Syst Evol Microbiol, 59(2), 275-279. https://doi.org/10.1099/ijs.0.000984-0

Kaplan, C. W., \& Kitts, C. L. (2004). Bacterial Succession in a Petroleum Land Treatment Unit. Appl Environ Microbiol, 70(3), 1777-1786. https://doi.org/10.1128/aem.70.3.1777-1786.2004

Keum, Y. S., Seo, J. S., Li, Q. X., \& Kim, J. H. (2008). Comparative metabolomic analysis of Sinorhizobium sp. C4 during the degradation of phenanthrene. Appl Microbiol Biotechnol, 80(5), 863-872. https://doi.org/10.1007/s00253-008-1581-4

Kouzuma, A., Pinyakong, O., Nojiri, H., Omori, T., Yamane, H., \& Habe, H. (2006). Functional and transcriptional analyses of the initial oxygenase genes for acenaphthene degradation from Sphingomonas sp. strain A4. Microbiology, 152(8), 2455-2467. https://doi.org/10.1099/mic.0.28825-0

Kurth, E. G., Doughty, D. M., Bottomley, P. J., Arp, D. J., \& Sayavedra-Soto, L. A. (2008). Involvement of BmoR and BmoG in n-alkane metabolism in 'Pseudomonas butanovora'. Microbiology, 154(1), 139-147. https://doi.org/10.1099/mic.0.2007/012724-0

\begin{tabular}{|c|c|c|c|c|c|}
\hline 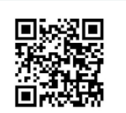 & (c) (1) (5) () & $\theta_{\text {AMEIENTIISS }}$ & $\frac{10 \%}{20}$ & $\frac{\text { UNA }}{\frac{\text { UNIVERSIDAD }}{\text { NACIONAL }}}$ & 203 \\
\hline
\end{tabular}




\section{Revista de CIENCIAS AMBIENTALES Tropical Journal of Environmental Sciences}

Revista de Ciencias Ambientales (Trop J Environ Sci) e-ISSN: 2215-3896 (Enero-Junio, 2022) . Vol 56(1): 178-208 DOI: https://doi.org/10.15359/rca.56-1.9 Open Access: www.revistas.una.ac.cr/ambientales e-mail: revista.ambientales@una.ac.cr

Rodríguez-Gonzales A., Zárate-Villarroel S., Bastida-Codina A.

Lai, Q., Li, W., \& Shao, Z. (2012). Complete genome sequence of Alcanivorax dieselolei type strain B5. Journal Bacteriology, 194(23), 66-74. https://doi.org/10.1128/JB.01813-12

Ławniczak, Ł., Wozniak-Karczewska, M., Loibner, A. P., Heipieper, H. J. \& Chrzanowski, L. (2020). Microbial Degradation of Hydrocarbons-Basic Principles for Bioremediation: A review. Molecules. 25(4), 1-19. https://doi.org/doi:10.3390/molecules25040856

Liang, Y., Zhao, H., Deng, Y., Zhou, J., Li, G., \& Sun, B. (2016). Long-Term Oil Contamination Alters the Molecular Ecological Networks of Soil Microbial Functional Genes. Front Microbiol, 7, 60. https://doi.org/10.3389/fmicb.2016.00060

Liao, J., Wang, J., Jiang, D., Wang, M. C., \& Huang, Y. (2015). Long-term oil contamination causes similar changes in microbial communities of two distinct soils. Appl Microbiol Biotechnol, 99(23), 10299-10310. https://doi.org/10.1007/s00253-015-6880-y

López, L., \& Infante, C. (2021). Cambios en los Biomarcadores de la fracción de hidrocarburos saturados en un ensayo de biorremediacion con un crudo extrapesado. Revista Internacional de Contaminación Ambiental, 37, 119-131. https://doi.org/10.20937/rica.53718

Lugo Mancilla, L. L. (2017). Interpretación conceptual del estado actual de la biorremediación realizada por microorganismos sobre hidrocarburos aromáticos policíclicos derivados del petróleo. [Tesis de maestría, Universidad de Manizales. Colombia]. Repositorio Institucional de la Universidad de Manizales. https://ridum.umanizales.edu.co/xmlui/handle/20.500.12746/4085

Luning Prak, D. J., \& Pritchard, P. (2002). Degradation of polycyclic aromatic hydrocarbons dissolved in Tween 80 surfactant solutions by Sphingomonas paucimobilis EPA 505. Canadian Journal of Microbiology, 48(2), 151-158. https://doi.org/10.1139/w02-004

Lyytikäinen, M., Pehkonen, S., Akkanen, J., Leppanen, M., \& Kukkonen, J. (2007). Bioaccumulation and biotransformation of polycyclic aromatic hydrocarbons during sediment tests with oligochaetes (Lumbriculus variegatus). Wiley-Blackwell, 26(12), 2660-2666. https://doi.org/10.1897/01-171.1

Mutnuri, S., Vasudevan, N., \& Kaestner, M. (2005). Degradation of anthracene and pyrene supplied by microcrystals and non-aqueous-phase liquids. Appl Microbiol Biotechnol, 67(4), 569-576. https://doi.org/10.1007/s00253-005-1905-6

Milic, J., Beskoski Vladimir, P., Ilic Mila, V., Samira Ali, A., Gordana Gojgic-Cvijovic, D., \& Miroslav Vrvic, M. (2009). Bioremediation of Soil Heavily Contaminated with Crude Oil and Its Products: Composition of the Microbial Consortium. Journal of the Serbian Chemical Society, 74(4), 455-460. https://doi.org/10.2298/jsc0904455m

\begin{tabular}{|c|c|c|c|c|c|}
\hline 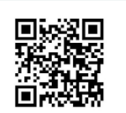 & (c) (1) (5) () & $\theta_{\text {AMEIENTIISS }}$ & $\frac{10 \%}{20}$ & $\frac{\text { UNA }}{\frac{\text { UNIVERSIDAD }}{\text { NACIONAL }}}$ & 204 \\
\hline
\end{tabular}




\section{Revista de CIENCIAS AMBIENTALES Tropical Journal of Environmental Sciences}

Revista de Ciencias Ambientales (Trop J Environ Sci) e-ISSN: 2215-3896 (Enero-Junio, 2022) . Vol 56(1): 178-208 DOI: https://doi.org/10.15359/rca.56-1.9 Open Access: www.revistas.una.ac.cr/ambientales e-mail: revista.ambientales@una.ac.cr

Rodríguez-Gonzales A., Zárate-Villarroel S., Bastida-Codina A.

Morais, D., Pylro, V., Clark, I. M., Hirsch, P. R., \& Totola, M. R. (2016). Responses of microbial community from tropical pristine coastal soil to crude oil contamination. PeerJ. 4, 1733. https://doi.org/10.7717/peerj.1733

Morante-Carriel L., Canchignia H.F., Morante-Carriel J., Romero-Meza R., Cedeño MoreriaA., Abasolo-Pacheco F. (2019). Becterias con potencialidades para la degradación de hidrocarburos en suelos contaminados de Quevedo, Ecuador.

Moyna Mendoza, D., Minchola Paredes, C., Castillo Quinto, P., Riquelme, Salas, A., \& Zavala Vásquez, D. (2021). Valoración Económica de los beneficios sociales del Río Corrientes, ante posibles daños ocasionados por la actividad petrolera en las comunidades aledañas a la plataforma Valencia, Loreto, 2021. https://hdl.handle.net/20.500.12788/150

Ocampo Hernández, C. E. (2021). El potencial de la biorremediacion. Universidad autonoma de Hidalgo, 2(2), 30-33. https://doi.org/10.29057/h.v2i2.6285

Patel, A. B., Shaikh, S., Jain, K. R., Desai, C., \& Madamwar, D. (2020). Polycyclic Aromatic Hydrocarbons: Sources, Toxicity, and Remediation Approaches. Front Microbiol, 11, 1-23. https://doi.org/10.3389/fmicb.2020.562813

Patel, V., Sharma, A., Lal, R., Al-Dhabi, N. A., \& Madamwar, D. (2016). Response and resilience of soil microbial communities inhabiting in edible oil stress/contamination from industrial estates. BMC Microbiol, 16, 1-14. https://doi.org/10.1186/s12866-016-0669-8

Pathak, A., Chauhan, A., Blom, J., Indest, K. J., Jung, C. M., Stothard, P., Bera, G., Stefan, J., \& Ogram, A. (2016). Comparative Genomics and Metabolic Analysis Reveals Peculiar Characteristics of Rhodococcus opacus Strain M213 Particularly for Naphthalene Degradation. PLoS One, 11(8), 1-32. https://doi.org/10.1371/journal.pone.0161032

Pereda Largo, E. (2010). Degradación de alcanos por células de alcanivorax Venustensis inmovilizadas en hidrogeles ddhesivos y biodegradables. [Tesis Doctoral, Universidad del País Vasco]. Ehubiblioteka. http://hdl.handle.net/10810/12269

Rakowska, J. (2020). Remediation of diesel-contaminated soil enhanced with firefighting foam application. Sci Rep, 10(1), 8824. https://doi.org/10.1038/s41598-020-65660-3

Ratledge, C. (1994). Biodegradation of oils, fats and fatty acids. En C. Ratledge (Eds) Biochemistry of microbial degradation (pp. 89-141). Springer, Dordrecht. https://doi.org/10.1007/978-94-011-1687-9_4

Romero Izquierdo, A. R. (2013). Biodegradación de HAPs durante la biorremediación aeróbica de suelos contaminados con hidrocarburos del petróleo. Análisis de poblaciones bacterianas y genes funcionales [Tesis Doctoral, Universidad de Barcelona]. Dipòsit Digital. http://hdl.handle.net/2445/53361

\begin{tabular}{|c|c|c|c|c|c|}
\hline 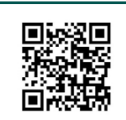 & (c) $\underset{\mathrm{BY}}{(1)} \mathrm{NG}_{\mathrm{SA}}$ & $\underset{\text { AMBIENTALES }}{\longrightarrow}$ & $\frac{O O}{2 \%}$ & $\frac{\text { UNA }}{\frac{\text { UNIVERSIDAD }}{\text { NACIONAL }}}$ & 205 \\
\hline
\end{tabular}




\section{Revista de CIENCIAS AMBIENTALES Tropical Journal of Environmental Sciences}

Revista de Ciencias Ambientales (Trop J Environ Sci) e-ISSN: 2215-3896 (Enero-Junio, 2022) . Vol 56(1): 178-208 DOI: https://doi.org/10.15359/rca.56-1.9 Open Access: www.revistas.una.ac.cr/ambientales e-mail: revista.ambientales@una.ac.cr

Rodríguez-Gonzales A., Zárate-Villarroel S., Bastida-Codina A.

Romero Lacal, J. (2008). Caracterización Bioquímica y Molecular del Sistema de dos Componentes TODS/TODT de Pseudomonas putida DOT-T1E [Tesis Doctoral, Universidad de Granada]. Digibug. https://digibug.ugr.es/handle/10481/1838

Ruan, B., Wu, P., Chen, M., Lai, X., Chen, L., Yu, L., Gong, B., Kang, C., Dang, Z., Shi, Z., \& Liu, Z. (2018). Immobilization of Sphingomonas sp. GY2B in polyvinyl alcohol-alginate-kaolin beads for efficient degradation of phenol against unfavorable environmental factors. Ecotoxicol Environ Saf, 162, 103-111. https://doi.org/10.1016/j.ecoenv.2018.06.058

Salgado, R., Pineda G., Mesta, A. M., Díaz F., \& Wang Hu, E. T. (2007). Degradación de n-alcanos por Pseudomonas Aeruginosa MGP1. Ciencia y Tecnología, 7(7). 123-132. https://dialnet.unirioja.es/servlet/articulo? codigo $=2986556$

Sayed, K., Baloo, L., \& Kumar, N. S. (2021). Bioremediation of Total Petroleum Hydrocarbons (TPH) by Bioaugmentation and Biostimulation in Water with Floating Oil Spill Containment Booms as Bioreactor Basin. Environmental Research and Public Health. 18(5), 1-26. http://doi.org/10.3390/ijerph18052226

Singleton, D. R., Lee, J., Dickey, A. N., Stroud, A., Scholl, E. H., Wright, F. A., \& Aitken, M. D. (2018). Polyphasic characterization of four soil-derived phenanthrene-degrading Acidovorax strains and proposal of Acidovorax carolinensis sp. nov. Syst Appl Microbiol. 41(5) 460-472. https://doi.org/10.1016/j.syapm.2018.06.001

Silva, C., Hayden, H., Sawbridge, T., Mele, P., Kruger, R., Rodrigues, M., Costa, G., Vidal, R., Sousa, M., Torres, A. P., Santiago, V., \& Oliveira, V. (2012). Phylogenetic and functional diversity of metagenomic libraries of phenol degrading sludge from petroleum refinery wastewater treatment system. AMB Express, 2(1), 2-13. https://doi.org/10.1186/2191-0855-2-18

Schuler, L., Jouanneau, Y., Chadhain, S., Meyer, S., Pouli, M., Zylstra, G., Hols, P., \& Agathos, S. (2009). Characterization of a ring-hydroxylating dioxygenase from phenanthrene-degrading Sphingomonas sp. strain LH128 able to oxidize benz[a] anthracene. Appl Microbiol Biotechnol. 83, 465-475. https://doi.org/10.1007/s00253-009-1858-2

Story, S. P., Kline, E. L., Hughes, T. A., Riley, M. B., \& Hayasaka, S. S. (2004). Degradation of aromatic hydrocarbons by Sphingomonas paucimobilis strain EPA505. Arch Environ Contam Toxicol, 47(2), 168-176. https://doi.org/10.1007/s00244-004-3069-2

Takeda, H., Shimodaira, J., Yukawa, K., Hara, N., Kasai, D., Miyauchi, K., \& Fukuda, M. (2010). Dual two-component regulatory systems are involved in aromatic compound degradation in a polychlorinated-biphenyl degrader, Rhodococcus jostii RHA1. J Bacteriol, 192(18), 47414751. https://doi.org/10.1128/JB.00429-10

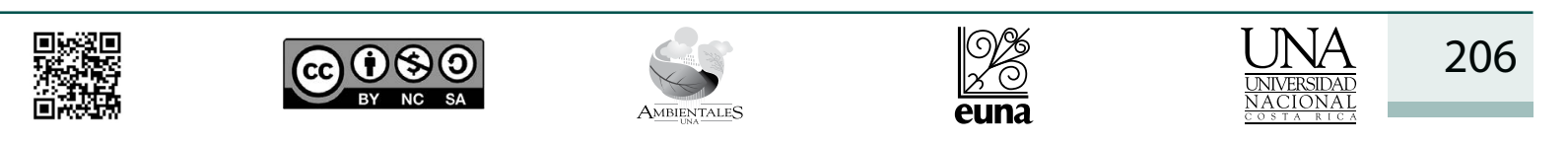




\section{Revista de CIENCIAS AMBIENTALES Tropical Journal of Environmental Sciences}

Revista de Ciencias Ambientales (Trop J Environ Sci) e-ISSN: 2215-3896 (Enero-Junio, 2022) . Vol 56(1): 178-208 DOI: https://doi.org/10.15359/rca.56-1.9 Open Access: www.revistas.una.ac.cr/ambientales e-mail: revista.ambientales@una.ac.cr

Rodríguez-Gonzales A., Zárate-Villarroel S., Bastida-Codina A.

Teramoto, M., Suzuki, M., Hatmanti, A. \& Harayama, S. (2010). The potential of Cycloclasticus and Altererythrobacter strains for use in bioremediation of petroleum-aromatic-contaminated tropical marine environments. J Biosci Bioeng, 110(1), 48-52. https://doi.org/10.1016/j.jbiosc.2009.12.008

Terrisse, F., Cravo-Laureau, C., Noel, C., Cagnon, C., Dumbrell, A. J., McGenity, T. J., \& Duran, R. (2017). Variation of Oxygenation Conditions on a Hydrocarbonoclastic Microbial Community Reveals Alcanivorax and Cycloclasticus Ecotypes. Front Microbiol, 8, 1-15. https://doi.org/10.3389/fmicb.2017.01549

Tyagi, M., da Fonseca, M. M., \& de Carvalho, C. C. (2011). Bioaugmentation and biostimulation strategies to improve the effectiveness of bioremediation processes. Biodegradation, 22(2), 231-241. https://doi.org/10.1007/s10532-010-9394-4

van Beilen, J. B., Marín, M. M., Smits, T. H., Röthlisberger, M., Franchini, A. G., Witholt, B., \& Rojo, F. (2004). Characterization of two alkane hydroxylase genes from the marine hydrocarbonoclastic bacterium Alcanivorax borkumensis. Environmental microbiology, 6(3), 264-273. https://doi.org/10.1111/j.1462-2920.2004.00567.x

Vandera, E., \& Koukkou, A. I. (2017). Bacterial Community Response to Hydrocarbon Contamination in Soils and Marine Sediments: A Critical Review of Case Studies. En C. Cravo-Laureau, C. Cagnon, B. Lauga, R. Duran (Eds) Microbial Ecotoxicology (pp. 185-226). Springer, Cham. https://doi.org/10.1007/978-3-319-61795-4_9

Viñas Canals, M. (2005). Biorremediación de suelos contaminados por hidrocarburos: caracterización microbiológica, química y ecotoxicológica. [Tesis Doctoral, Universidad de Barcelona]. TDX. https://www.tdx.cat/handle/10803/2396;jsessionid=ACCA48A91A591A99376F8685B960F04B\#page $=1$

Watkinson R. J., \& Morgan P. (1991). Physiology of aliphatic hydrocarbon-degrading microorganisms. En C. Ratledge (eds) Physiology of Biodegradative Microorganisms (pp. 79-92). Springer, Dordrecht. https://doi.org/10.1007/978-94-011-3452-1_1

Wong-Villarreal A., Santiago-Mendez E., Hernández-Núñez E., Yáñez-Ocampo G., Giácoman-Vallejos G., González-Sánchez A., Ramírez-González, S., Espinosa-Zaragoza, S. \& López-Báez, O. (2017). Degradación de Fenantreno por bacterias del género Burkholderia y Rhizobium aisladas de nódulos de mimosas. NOVA-Scientia, 9(19), 291-305. https://doi.org/10.21640/ns.v9i19.995

Xu, Y., Yu, M., \& Shen, A. (2016). Complete Genome Sequence of the Polychlorinated Biphenyl Degrader Rhodococcus sp. WB1. American Society for Microbiology, 4(5), 1-2. https://doi. org/10.1128/genomeA.00996-16

\begin{tabular}{|c|c|c|c|c|c|}
\hline 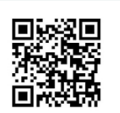 & (c) (1) (5) () & $\underbrace{}_{\text {AMBENTIIES }}$ & $\frac{10 \%}{20}$ & $\frac{\text { UNA }}{\frac{\text { UNIVERSIDAD }}{\text { NACIONAL }}}$ & 207 \\
\hline
\end{tabular}




\section{Revista de CIENCIAS AMBIENTALES Tropical Journal of Environmental Sciences}

Revista de Ciencias Ambientales (Trop J Environ Sci) e-ISSN: 2215-3896 (Enero-Junio, 2022) . Vol 56(1): 178-208 DOI: https://doi.org/10.15359/rca.56-1.9 Open Access: www.revistas.una.ac.cr/ambientales e-mail: revista.ambientales@una.ac.cr

Rodríguez-Gonzales A., Zárate-Villarroel S., Bastida-Codina A.

Yamazoe, A., Yagi, O., \& Oyaizu, H. (2004). Biotransformation of fluorene, diphenyl ether, dibenzo-p-dioxin and carbazole by Janibacter sp. Biotechnology Letters, 26, 479-486. https://doi.org/10.1023/B:BILE.0000019554.49484.40

Zampolli, J., Collina, E., Lasagni, M., \& Di Gennaro, P. (2014). Biodegradation of variable-chain-length n-alkanes in Rhodococcus opacus $\mathrm{R7}$ and the involvement of an alkane hydroxylase system in the metabolism. AMB Express, 4. 73(1), 2-9. https://doi.org/10.1186/s13568-014-0073-4

Zanaroli, G., Di Toro, S., Todaro, D., Varese, G. C., Bertolotto, A., \& Fava, F. (2010). Characterization of two diesel fuel degrading microbial consortia enriched from a non acclimated, complex source of microorganisms. Microb Cell Fact, 9(10), 1-9. https://doi.org/10.1186/1475-2859-9-10

Zhao, Q., Yue, S., Bilal, M., Hu, H., Wang, W., \& Zhang, X. (2017). Comparative genomic analysis of 26 Sphingomonas and Sphingobium strains: Dissemination of bioremediation capabilities, biodegradation potential and horizontal gene transfer. Sci Total Environ, 609(1), 1238-1247. https://doi.org/10.1016/j.scitotenv.2017.07.249

Zhang, X., Yang, L., Zhang, H., Xing, W., Wang, Y., Bai, P., Zhang, L., Hayakawa, K., Toriba, A., Wei, Y., \& Tang N (2021). Assessing Approaches of Human Inhalation Exposure to Polycyclic Aromatic Hydrocarbons: A Review. International journal of Environmental research and Public Health. 18(6), 3124. http://doi.org/10.3390/ijerph18063124

Zhou, R., Huang C., Zhang, A., Bell, S. G., Zhou, W., \& Wong, L. (2011). Crystallization and preliminary X-ray analysis of CYP153C1 from Novosphingobium aromaticivorans DSM12444. Acta Crystallogr Sect F Struct Biol Cryst Commun, 67(8), 964-967. https://doi.org/10.1107/S174430911102464X

\begin{tabular}{|c|c|c|}
\hline 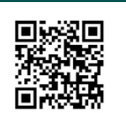 & (c) $\underset{\mathrm{BY}}{(\mathrm{i})(\mathrm{NC}} \mathrm{SA}_{\mathrm{SA}}$ & 208 \\
\hline
\end{tabular}

